\title{
The role of cementation in the behaviour of cemented soils
}

1 Poul V. Lade PhD

Professor, Department of Civil Engineering, The Catholic University of America, Washington DC, USA
2 Niels Trads PhD

Senior Project Manager, Geo, Kongens Lyngby, Denmark
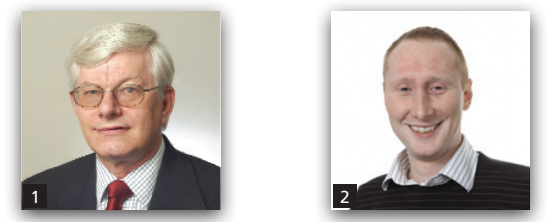

The behaviour of cemented soil and the role of cementation are reviewed based on experimental results. The review is presented in terms of geomechanics concepts in which the cemented soil may be modelled by elasticity and hardening plasticity concepts. No modelling equations are given, but the observed behaviour is analysed in view of the components entering into an elastoplastic model. These consist of an elastic range in stress space in which energy is not created or expended, a cementation yield surface, a 3D failure surface, a plastic potential, a yield surface and the associated plastic hardening law.

\section{Notation}

b $\quad\left(\sigma_{2}-\sigma_{3}\right) /\left(\sigma_{1}-\sigma_{3}\right)$

CD consolidated drained

$D_{\mathrm{r}} \quad$ relative density

E Young's elastic modulus

e void ratio

$e_{0} \quad$ initial void ratio

$H_{\mathrm{c}} \quad$ critical hardening modulus

$K_{0} \quad$ coefficient of earth pressure at rest

$p \quad$ mean normal stress

$p_{\text {a }} \quad$ atmospheric pressure

$q \quad\left(\sigma_{1}-\sigma_{3}\right)=$ deviator stress

$\varepsilon_{1} \quad$ axial strain

$\varepsilon_{\mathrm{v}} \quad$ volumetric strain

$\sigma_{1} \quad$ major principal stress

$\sigma_{3} \quad$ minor principal stress or confining pressure

$\sigma_{1} / \sigma_{3}$ principal stress ratio

$\sigma_{\mathrm{c}} \quad$ consolidation pressure

$\phi \quad$ friction angle

$\phi_{\mathrm{cl}} \quad$ characteristic state friction angle

$\phi_{\text {crit }} \quad$ critical state friction angle

$\phi_{\mathrm{cv}} \quad$ constant volume friction angle

$\phi_{\text {peak }}$ peak friction angle

$\psi_{\text {peak }}$ peak angle of dilation

\section{Introduction}

The role of cementation in the behaviour of soils is addressed based on experimental observations from clean sands and cemented sands. The behaviour pattern of cemented sand is influenced by the underlying behaviour of clean sand. Therefore, to understand the effects of cementation, the behaviour of normally consolidated and overconsolidated sand under drained conditions is briefly reviewed first. This is followed by a review of observed behaviour of cemented soils, and a conceptual model for the behaviour of cemented soil is presented. Drained experiments on cemented sand (mortar) with particular stress paths are performed with the express intent of checking some salient points in the conceptual model.

The differences in behaviour of sand and cemented soil are seen from a geomechanics point of view, that is, in view of elasticity and plasticity theories used to model the behaviour. Thus, failure, yield and plastic potential surfaces are of primary interest in the presentation of the sand and cemented soil behaviour patterns. The variables that play the most important roles are the density, the confining pressure and the amount of cementation. Clean sands show no cementation effects, whereas high-strength concrete contains a cementation zone that is so large that it is difficult to exceed because of the requirement of high stresses in the experiments. The entire picture of behaviour can best be seen from tests on soils with low amounts of cementation because this material contains all facets of behaviour inside and outside the cemented zone. A smooth transition occurs between the fully cemented zone and the fully plastic zone, and this may disguise the yield surface location in the transition zone. The effects of anisotropy are important, but this issue is outside the scope of this presentation. 


\section{Drained behaviour of sand}

\section{Isotropic compression}

The effect of initial relative density on the isotropic compression curves for Cambria sand tested at relative densities of $30 \%, 60 \%$ and $90 \%$ is shown in Figure 1 (Lade and Bopp, 2005). The curves resemble those obtained from clays for which plastic yield points are determined near the maximum curvature on the $e-\log \left(p^{\prime}\right)$ curves. Below these yield points, the clays are overconsolidated and they behave nearly elastically, while sands behave plastically because of grain rearrangement. Beyond the point of maximum curvature, grain crushing is initiated, and this produces considerable contraction of the sand. After application of confining pressures higher than $15 \mathrm{MPa}$, the Cambria sand specimens with different initial void ratios have approximately the same void ratio for a given isotropic confining pressure. Similar conclusions have been made by other investigators for isotropic and $K_{0}$ compression of sands (e.g. Pestana and Whittle, 1995; Yamamuro et al., 1996). This also conforms closely to results produced by Vesic and Clough (1968), who concluded that the initial void ratio does not seem to have any effect on the behaviour of specimens consolidated to pressures above $20 \mathrm{MPa}$ for Chattahoochee River sand. Similarly, Miura and Yamanouchi (1973) found that the effect of initial density on the stress-strain relationship decreases with increasing confining pressure. However, they concluded that even at high confining pressures such as $50 \mathrm{MPa}$, the initial density continued to have some influence on the stress-strain relationships.

With increasing confining pressure, a greater degree of particle crushing and grain rearrangement occurs during the isotropic

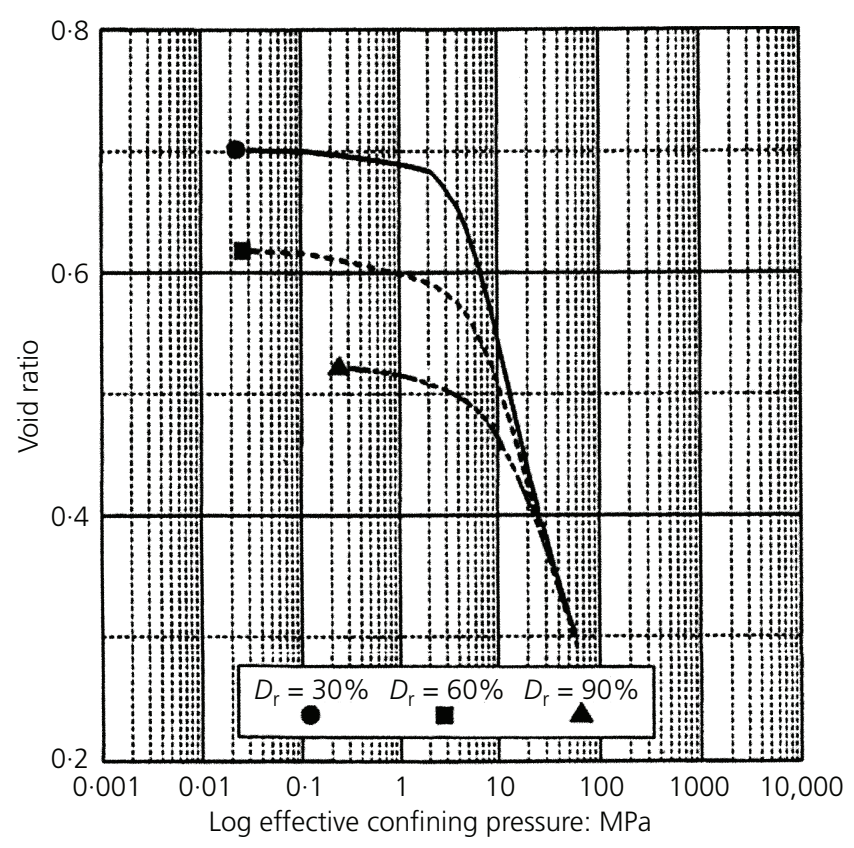

Figure 1. Void ratio related to isotropic confining pressure for loose, medium dense, and dense Cambria sand compression phase, and the effect of initial relative density on the behaviour during shear is progressively reduced. For tests with confining pressures greater than $15 \mathrm{MPa}$, the stress-strain, volume change (drained tests) or pore pressure curves (undrained tests) for specimens of Cambria sand at the same consolidation pressure are very similar, and the effect of initial relative density appears to be negligible (Bopp and Lade, 2005; Lade and Bopp, 2005).

\section{Stress-strain and volume change behaviour}

The two most important factors that control the stress-strain and volume change behaviour of sands are the effective confining pressure and the void ratio. Figure 2(a) shows the effect of confining pressure on the results of drained triaxial compression tests on medium-dense Sacramento River sand $\left(e_{0}=0 \cdot 71, D_{\mathrm{r}}=\right.$ 78\%) (Lee, 1965). The stress-strain curves are highly non-linear, and their shapes change considerably over the 24-fold increase in confining pressure, the friction angle calculated from the effective stress ratio decreases, the strain-to-failure increases, and the initial modulus increases in a non-linear fashion with increasing confining pressure (not shown in Figure 2(a)).

The corresponding volumetric strains, plotted on Figure 2(b), indicate initial contraction followed by dilation at low confining pressures with gradual transition to further contraction at high confining pressures. The volumetric strain rate at failure is tied to the variation in friction angle observed from the stress-strain relations, as indicated by Rowe (1962) and by Bishop (1966).

Figure 3(a) shows the effect of void ratio or density on the results of drained triaxial compression tests on Sacramento River sand performed with the same confining pressure of $300 \mathrm{kPa}$ (Lee, 1965). The stress-strain curves are highly non-linear, and their shapes change considerably as the void ratio changes from dense to loose. The friction angle calculated from the effective stress ratio decreases, the strain-to-failure increases, and the initial modulus decreases in a non-linear fashion with a decreasing void ratio (not shown in Figure 3(a)).

The corresponding volumetric strains, plotted on Figure 3(b), indicate initial contraction followed by dilation for low void ratios with gradual transition to further contraction for high void ratios. As explained above, the volumetric strain rate at failure is tied to the variation in friction angle observed from the stress-strain relations.

The typical variation of the drained shear strength of sand with confining pressure is illustrated schematically in Figure 4(a). For a sand with a given void ratio, the peak friction angle, $\phi_{\text {peak }}^{\prime}$, consists of two components: one from the basic friction between sand particles modified by contributions for rearrangement of particles at constant volume. The resulting friction angle is referred to as $\phi_{\mathrm{cv}}^{\prime}$ $\left(\mathrm{cv}=\right.$ constant volume) or the critical friction angle, $\phi_{\text {crit. }}^{\prime}$ The second component derives from the rate of dilation of the sand during shear, $\psi_{\text {peak }}$. When the rate of dilation reaches its highest value, it creates the peak failure condition. Therefore, as shown in Figure 5: 


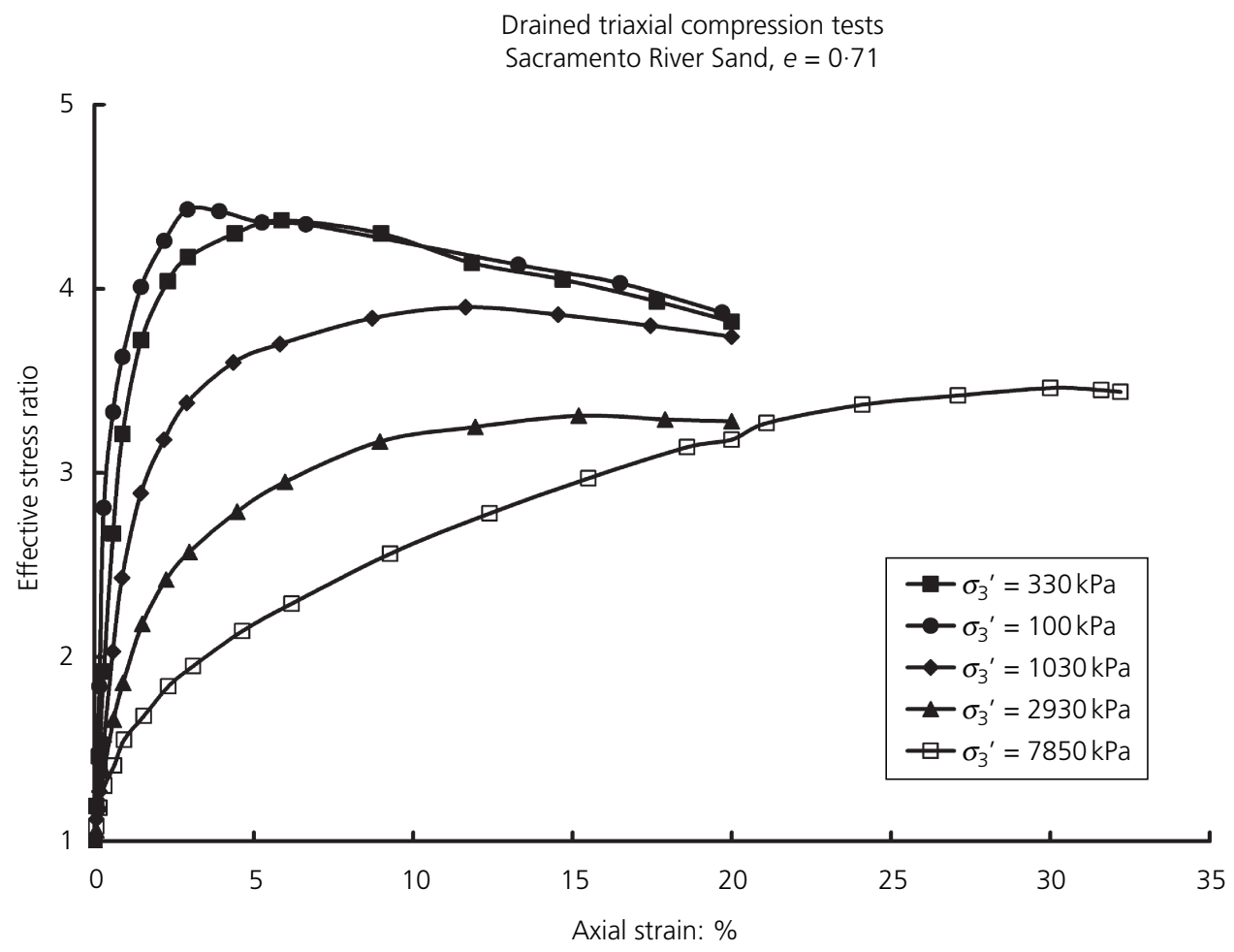

(a)

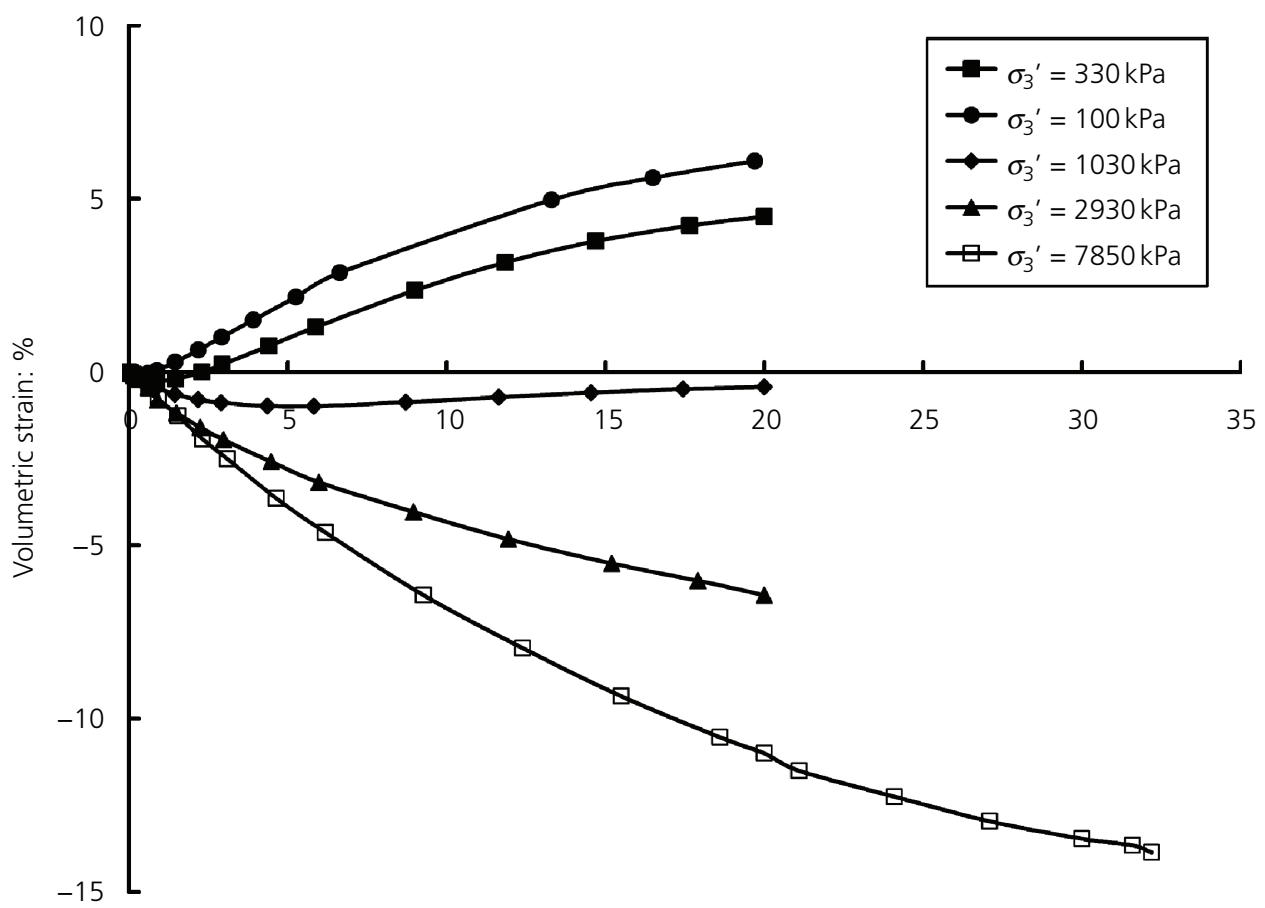

Axial strain: \%

(b)

Figure 2. Effect of confining pressure on drained stress-strain and volume change behaviour of medium dense Sacramento River sand in triaxial compression tests (after Lee (1965)) 


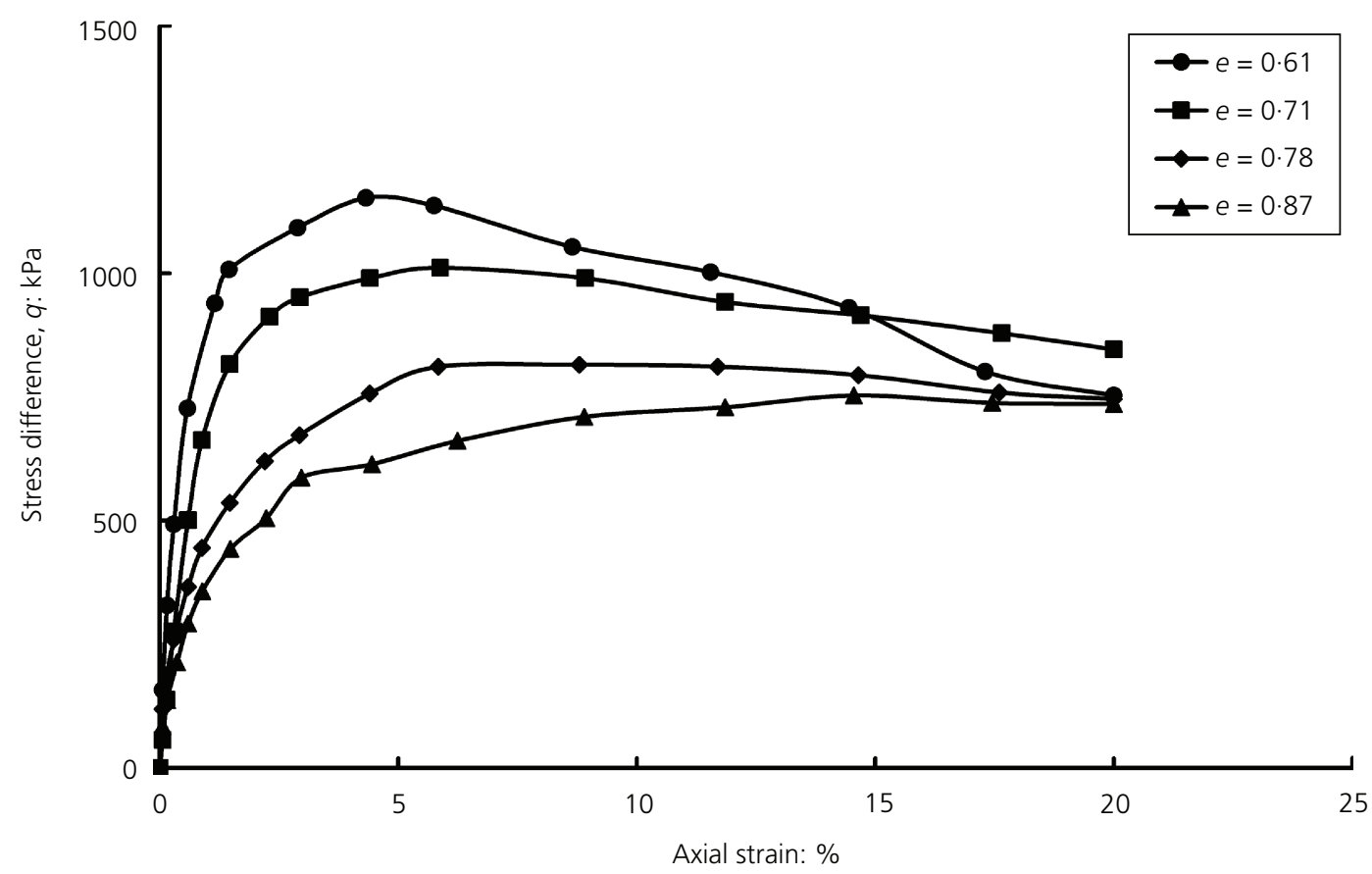

(a)

Drained triaxial compression tests

Sacramento River Sand, $\sigma_{3}=300 \mathrm{kPa}$

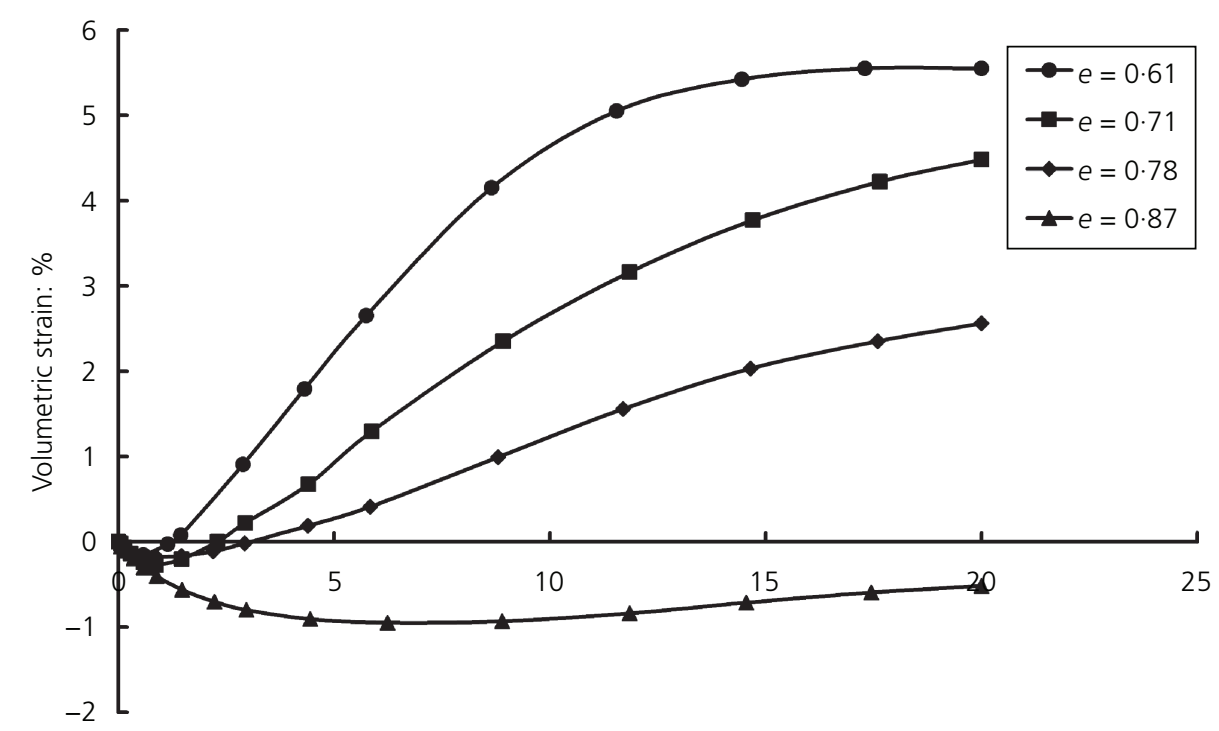

Axial strain: \%

(b)

Figure 3. Effect of the initial void ratio on drained stress-strain and volume change behaviour of Sacramento River sand in triaxial compression tests performed with a confining pressure of $300 \mathrm{kPa}$ (after Lee (1965)) 
Geotechnical Research

Volume 1 Issue 4
The role of cementation in the behaviour

of cemented soils

Lade and Trads

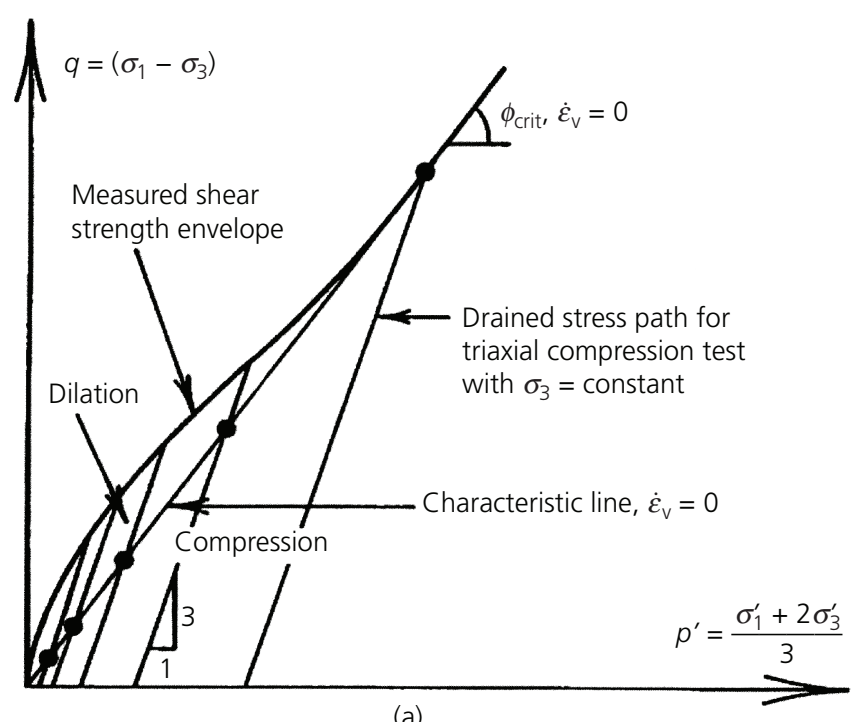

(a)

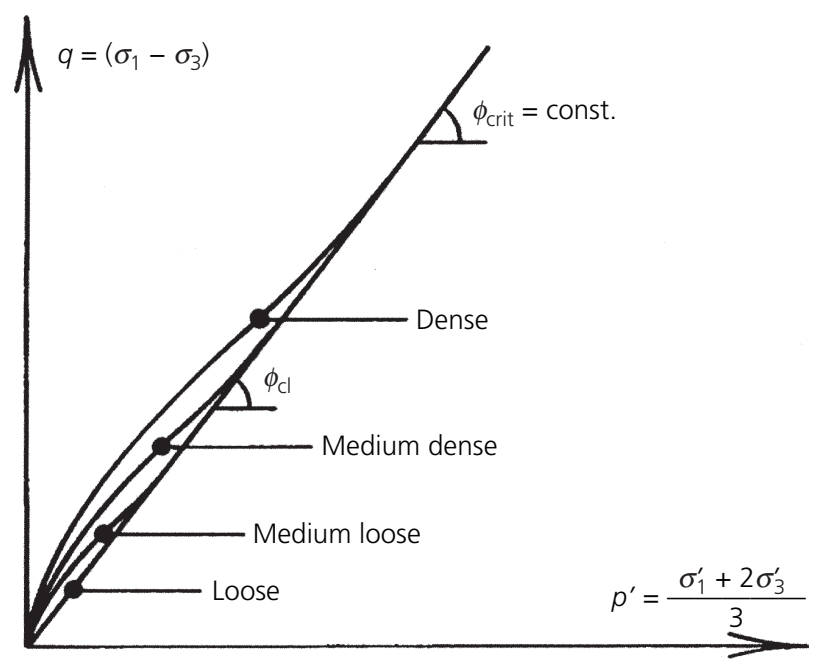

(b)

Figure 4. Schematic illustrations of variation of drained shear strength envelope for sand with (a) confining pressure and (b) relative density

1. $\phi_{\text {peak }}^{\prime}=\phi_{\mathrm{cv}}^{\prime}+\psi_{\text {peak }}$

The value of $\phi_{c v}^{\prime}$ is essentially independent of the void ratio for a given sand, but it may vary a little with confining pressure (Lade and Ibsen, 1997). The dilation is suppressed at higher pressures because of crushing, and the resulting strength component, $\psi_{\text {peak }}$, therefore reduces to zero at very high pressures. Thus, a curved failure surface is observed. Experiments on sands have shown that both the contribution from dilation and the range of confining pressures in which dilation occurs reduce with increasing void ratio and decreasing relative density, as shown schematically in Figure 4(b).

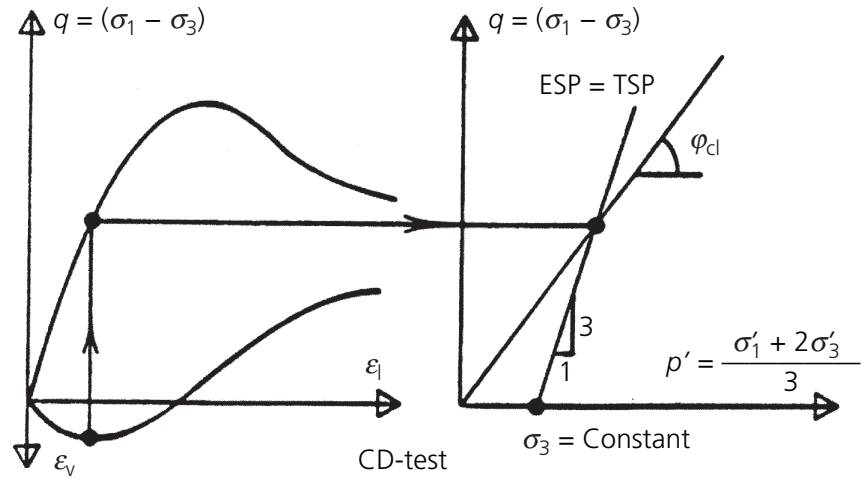

Figure 5. Schematic illustrations of characteristic and critical states and of strength parameters in drained test on sand shown in

(a) stress-strain and volume change diagram and (b) $p^{\prime}-q$ diagram

\section{Characteristic line}

The separation between the region of contraction and the region of dilation for drained tests on sand occurs at the characteristic state at which the rate of volume change is zero, $\delta \varepsilon_{v} / \delta \varepsilon_{1}=0$ (Luong, 1982), as shown schematically in Figure 5. Characteristic states occur at the transition from contraction to dilation, and these states are located on a straight line, the characteristic line, through the stress origin. The slope of the characteristic line may be described by an angle, $\phi_{\mathrm{cl}}$. The characteristic state and the critical state are very similar, as discussed by Luong (1982). For loose sand and sand at high confining pressure, $\delta \varepsilon_{\mathrm{v}} / \delta \varepsilon_{1}=0$ is reached at the critical state, which is therefore the same as the characteristic state, and it occurs at failure for sand that contracts during shear. For dense sand or sand at low confining pressure, the characteristic state is reached at small strain magnitudes, as indicated in Figure 5, while the critical state is reached at large strains.

The characteristic line divides the stress space into two subspaces in which the stress combinations lead to different deformation mechanisms. Below the characteristic line, the stress combinations lead to contraction, that is, $\delta \varepsilon_{\mathrm{v}}>0$, and the resistance to deformation is governed by sliding friction due to microscopic interlocking depending on the surface roughness of the particles or interlocking friction between particles. According to Luong (1982), the resistance is due to pure friction, and the characteristic state is described by an intrinsic parameter, the characteristic angle, $\phi_{\mathrm{cl}}$, for a given sand. Above the characteristic line, the stress combinations lead to dilation, that is, $\delta \varepsilon_{\mathrm{v}}<0$, and the resistance to deformation is governed by rupture of interlocking and volumetric dilation.

The stress states corresponding to $\delta \varepsilon_{\mathrm{v}}=0$ for triaxial compression tests on Santa Monica Beach sand at four void ratios (Lade and Prabucki, 1995) are shown in Figure 6. These experiments were performed on specimens with a height-to-diameter ratio of 2.65 and with lubricated ends. They show that the characteristic angle $\phi_{\mathrm{cl}}$ is independent of the void ratio for a given sand and that it varies a little with confining pressure. 
The role of cementation in the behaviour of cemented soils

Lade and Trads

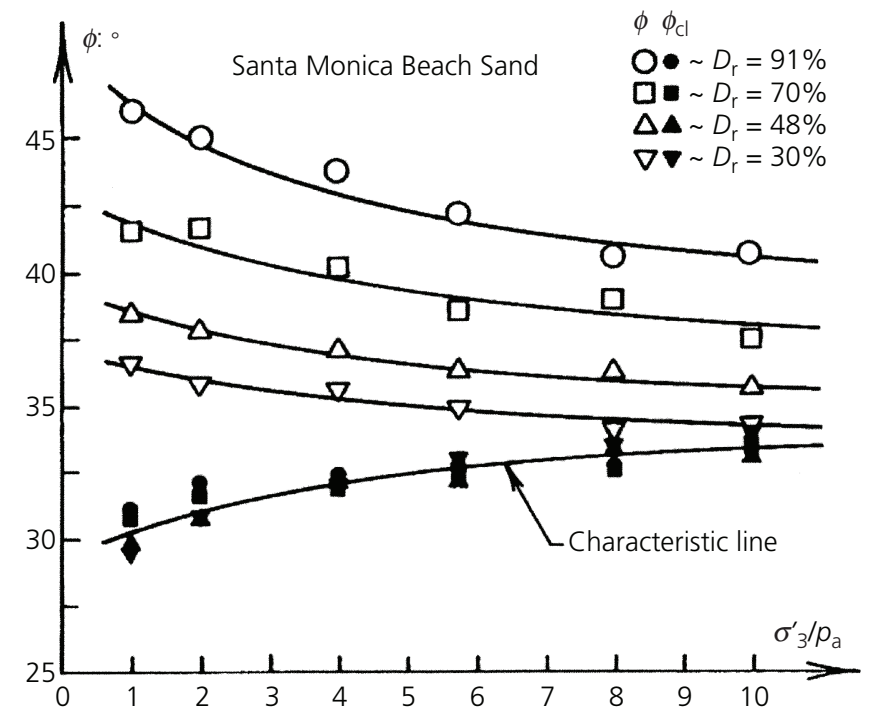

Figure 6. Friction angles and characteristic states obtained from triaxial compression tests on Santa Monica beach sand at four different void ratios

\section{Smooth peak failure}

The friction angle calculated for failure conditions is the secant friction angle, and this decreases with increasing confining pressure for all void ratios, as indicated in Figure 6 for Santa Monica Beach sand (Lade and Prabucki, 1995). Smooth peak failure is observed in all triaxial compression tests on sand, irrespective of the void ratio, as shown in Figure 3(a). Thus, the peak stress difference is encountered during homogeneous deformation of the sand specimens.

\section{Shear banding}

The location on the stress-strain curve from the triaxial compression test shown in Figure 7 at which the first observation of a shear plane was made is indicated in the diagram. Considerable straining beyond the peak failure point may be required before shear bands occur in triaxial compression tests on sand. In fact, shear banding always occurs in the softening regime in triaxial compression tests in which $b=\left(\sigma_{2}-\sigma_{3}\right) /\left(\sigma_{1}-\sigma_{3}\right)=0 \cdot 0$. The stress-strain curve clearly shows a drop in strength, and the rate of dilation diminishes substantially immediately before the shear plane becomes visible. Thus, the reduced rate of dilation appears to be associated with the occurrence of the shear band and the achievement of critical state conditions within the shear plane. Once a shear band has developed fully, the stresses and the volume changes tend to level off, the specimen outside the developing shear band unloads elastically, and the material inside the shear band loosens up to the critical void ratio (Desrues et al., 1996) and rapidly becomes weaker than the remaining major parts of the specimen.

Experimental results with respect to the formation of shear bands under various stress conditions are available from previous investigations (e.g. Arthur et al., 1977; Desrues et al., 1985, 1996; Finno et al., 1996, 1997; Nemat-Nasser and Okada, 2001; Tatsuoka et

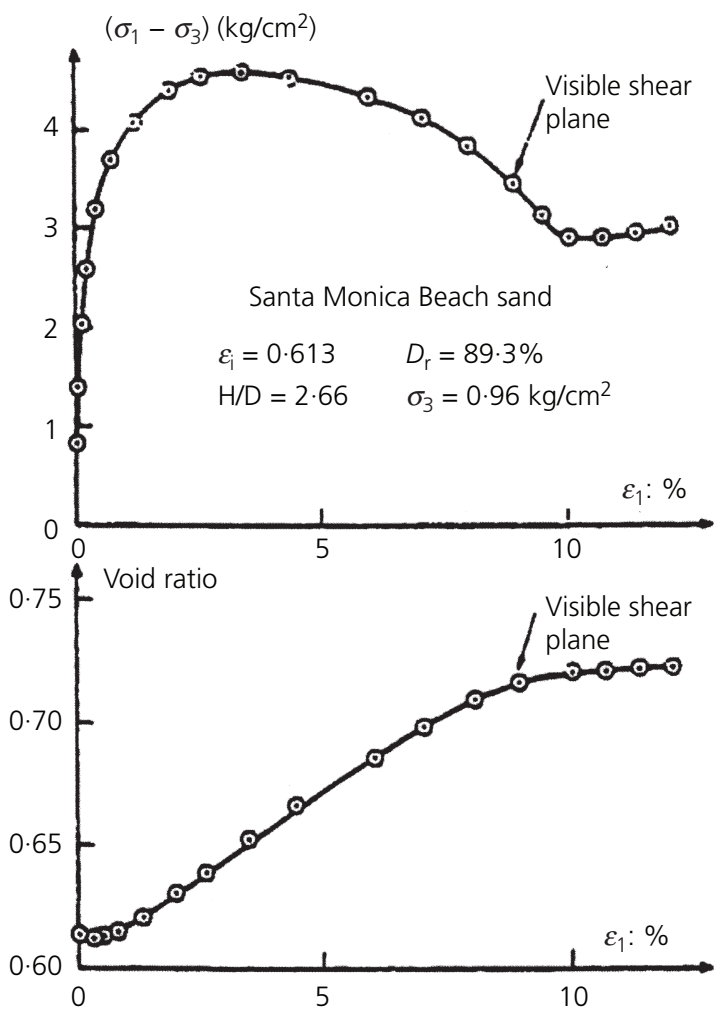

Figure 7. Stress-strain relation and void ratio change from triaxial compression test exhibiting strain-softening and development of shear plane

al., 1990; Vardoulakis, 1980; Yoshida et al., 1993), while theoretical developments and predictions have been attempted in other studies (e.g. Hansen, 1958; Molenkamp, 1985; Muhlhaus and Vardoulakis, 1987; Rice, 1976; Rudnicki and Rice, 1975; Vardoulakis, 1980, 1996a, 1996b; Vardoulakis et al., 1978; Vermeer, 1982).

Experimental studies of shear banding in true triaxial tests have been performed (Wang and Lade, 2001). The 3D strength characteristics and the influence of strain localisation and shear banding on failure were studied, and the peak strengths were compared with the failure criterion proposed by Lade (1977). Quantitative comparisons were made between the critical conditions for shear band formation obtained from experiments (Lade and Wang, 2001) and from theoretical considerations and expressed by the dimensionless hardening parameter $H_{\mathrm{d}} / E$ immediately prior to the onset of shear banding (Lade, 2003). Figure 8 presents a comparison between measured and predicted friction angles for the true triaxial tests on dense Santa Monica Beach sand. Shear banding occurs in the hardening regime and controls the strength in the middle range of $b$ values, both according to the measured and the predicted results. Thus, the failure surface for granular material is not a smooth surface that can be described by a single expression, and a smooth peak failure is obtained only for the extreme values of $b$ near zero and unity, while shear banding causes failure in the midrange of $b$ values, including plane strain. 
The role of cementation in the behaviour of cemented soils

Lade and Trads

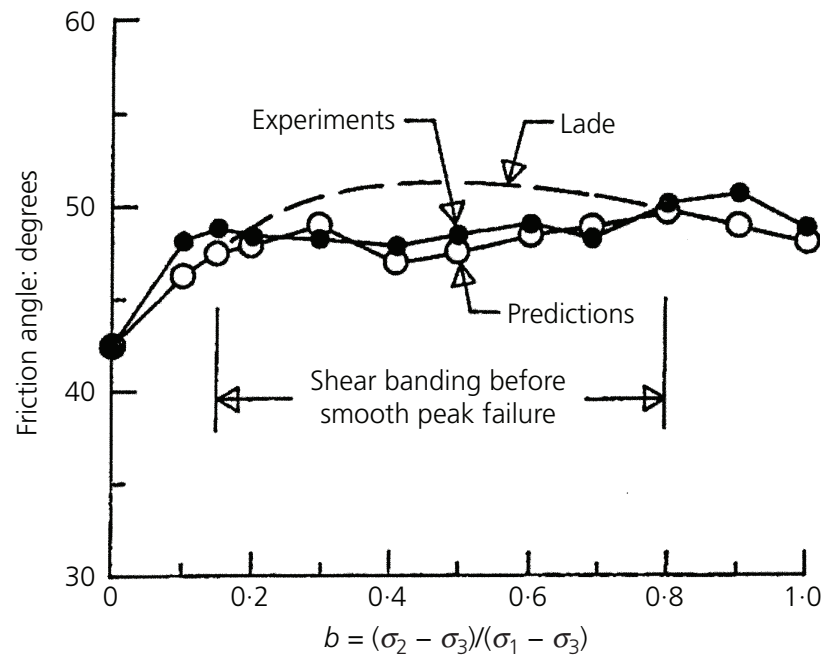

Figure 8. Comparison of measured and predicted friction angles for true triaxial tests on dense Santa Monica Beach sand. Shear banding controls strength in the middle range of $b$ values.

\section{Critical state and steady state line}

As the stress-strain relation reaches into the softening regime for sand that dilates, the strength declines towards the critical state or steady state at which further shearing will occur with no further change in volume and in effective stresses (Casagrande, 1936). However, the critical state is not reached in the entire specimen, but only in the shear band that develops in the dilating sand. Thus, critical state is only reached in loose sands that contract uniformly and in which the strength increases and does not exhibit a peak. The line of critical states goes through the origin of the stress space; it may be characterised by a friction angle, $\phi_{\text {crit }}$, and experiments show that $\phi_{\mathrm{cl}}=\phi_{\text {crit }}$.

\section{Yield surfaces}

Various yield criteria expressing combinations of multiaxial stresses that will cause plastic yielding have been proposed in the literature. These criteria have most often been based on experimental observations, sometimes in combination with assumptions about the type of plastic behaviour exhibited by the material (associated or non-associated flow). However, in plasticity theory, yield surfaces must be associated with hardening (and softening) parameters such that the combination uniquely defines the magnitude of incremental plastic strains.

A constitutive model has been developed based on thorough review and evaluation of data from experiments on frictional materials such as sand, clay, concrete and rock (Kim and Lade, 1988; Lade and Kim, 1988a, 1988b). This model employs a single, isotropic yield surface that expresses a contour of constant plastic work as measured from the origin of stress. It is expressed in terms of stress invariants, and is shaped as an asymmetric teardrop with the pointed apex at the origin of the principal stress space, as shown in Figure 9. For an isotropic material, the yield surface intersects

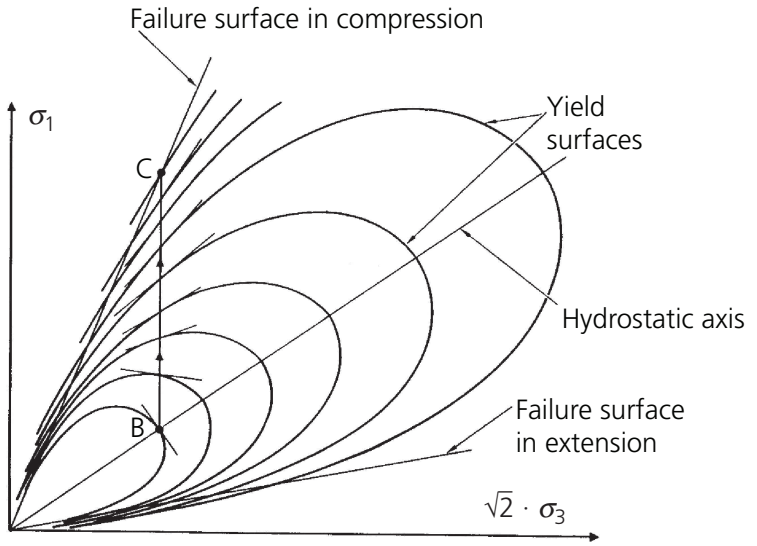

Figure 9. Pattern of yield surfaces for isotropic granular materials. Stress path in conventional triaxial compression test (BC).

the hydrostatic axis in a perpendicular manner, bends smoothly backwards towards the origin and crosses the failure surface at sharp angles, as shown in Figure 9. This yield surface, expressed in terms of stress invariants, describes the locus at which the total plastic work is constant. The total plastic work (due to shear strains as well as volumetric strains) serves as the hardening parameter, and is used to define the location and shape of the yield surface. The use of contours of constant plastic work as yield surfaces results in mathematical consistency in the model because the measure of yielding and the measure of hardening are uniquely related through one monotonic function. In addition, application of a single yield surface produces computational efficiency when used in large computer programs.

The teardrop-shaped yield surface described above embodies the findings presented by Tatsuoka and Ishihara (1974) and by Parry and Nadarajah (1973). In conjunction with the non-associated flow rule, it correctly models the coupling effects discussed above. This model of the yield surface will be used in evaluation of the experimental results produced for the study of softening and preshearing effects in sand presented below.

\section{Effects of preshearing and overconsolidation}

\section{Effects in the hardening regime}

To demonstrate the effects of preshearing in the hardening regime, two specimens of loose Santa Monica Beach sand were consolidated along stress paths corresponding approximately to $K_{0}$ conditions, as shown in Figure 10. Both stress paths start at point A on the hydrostatic axis. They then follow approximately the same constant stress ratio, corresponding to $K_{0}=$ constant, to point B. One specimen is then unloaded along a $K_{0}$ unloading branch to point $\mathrm{C}$ on the hydrostatic axis and then loaded to failure at constant confining pressure. The second specimen is unloaded from point $\mathrm{B}$ to point $\mathrm{D}$ along the same stress path as followed during loading and then loaded to failure at constant confining pressure. 
The role of cementation in the behaviour

of cemented soils

Lade and Trads

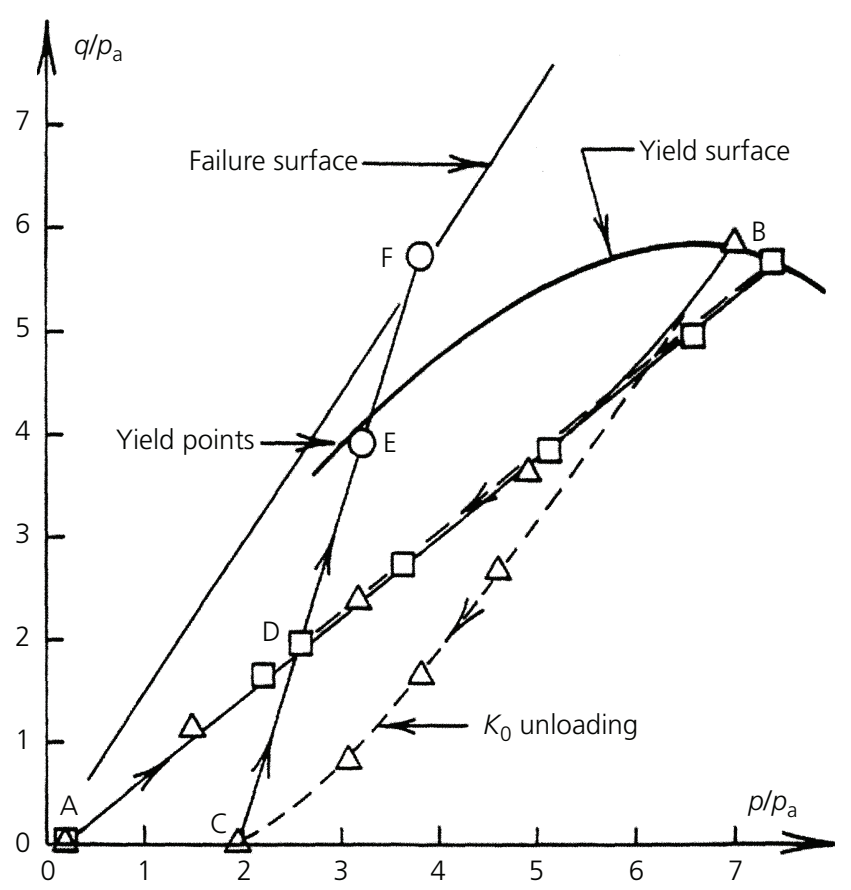

Figure 10. Stress paths employed to study effects of prestressing on yielding in the hardening regime for loose Santa Monica Beach sand

The specimens in the two stress path tests are clearly overconsolidated in the sense that essentially elastic behaviour is obtained upon loading from points $\mathrm{C}$ and $\mathrm{D}$ to point $\mathrm{E}$, and the yield points (E) are essentially the same for the two tests. The teardropshaped yield surface shown in Figure 10 corresponds to a contour of constant plastic work as explained above. The stress-strain relations beyond the yield point were found to correspond well with that from a third specimen sheared at constant confining pressure from point $\mathrm{C}$ to peak failure at point $\mathrm{F}$. Thus, the strengths obtained from the three specimens were essentially the same and within the scatter of results obtained in such studies.

\section{Effects of preshearing to peak failure}

Following preshearing to peak failure at a confining pressure of $\sigma_{3} / p_{\mathrm{a}}=10\left(p_{\mathrm{a}}=\right.$ atmospheric pressure in the same units as $\left.\sigma_{3}\right)$ of triaxial specimens of Santa Monica Beach sand, the yield surface was sought again in the range of lower confining pressures, as shown in Figure 11 (Lade and Prabucki, 1995). Figure 12 shows the principal stress ratio-axial strain and the volumetric strain-axial strain relations from a test on dense sand. It is clear that very small strains were produced during a cycle in stress difference, that is, the sand grains hardly moved inside the yield surface. Once the yield surface was encountered, the specimen indicated higher rates of volumetric dilation than was observed during loading up to peak failure.

The maximum yield points, in fact, represent the peak failure conditions. Although the stress differences decrease, the maximum

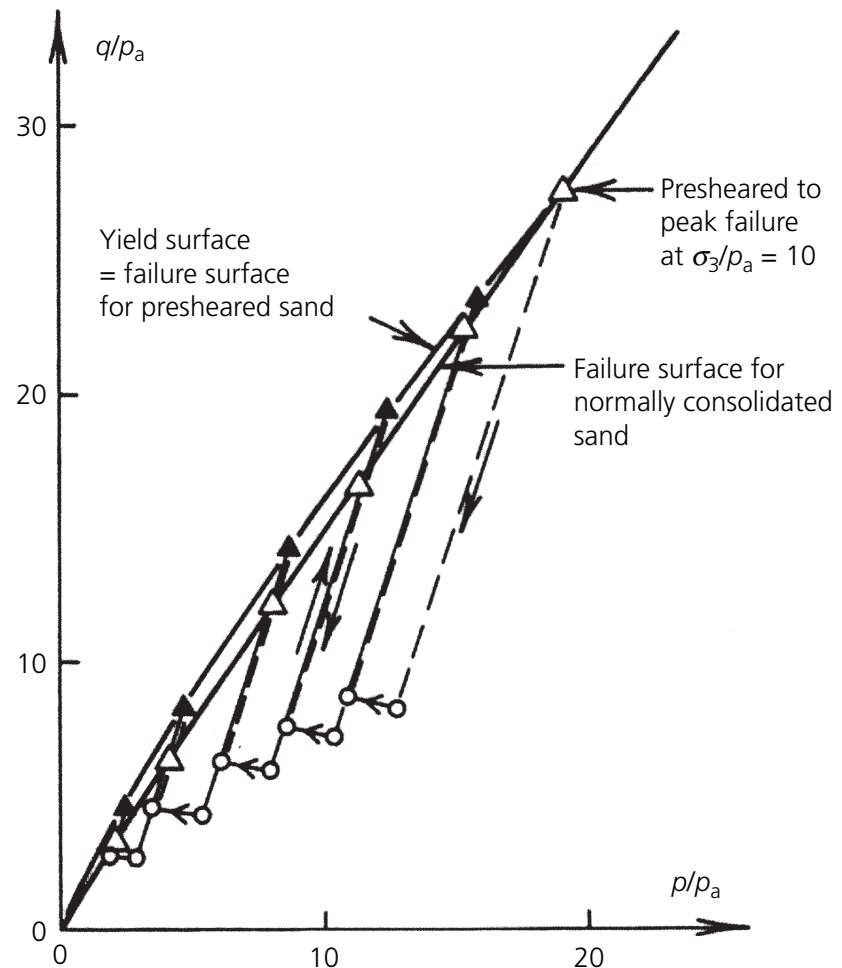

Figure 11. Stress paths with decreasing mean normal stress and stress probes to determine the location of yield surface for presheared medium loose Santa Monica Beach sand

stress ratios increase with decreasing confining pressure, and they become larger than those for normally consolidated sand. Thus, the yield surface crosses the failure surface for normally consolidated sand, and it becomes the failure surface in the region of lower stresses. The overall pattern of behaviour is indicated in Figure 13. Once the yield surface is established by preshearing or by overconsolidation, it crosses the failure surface for the normally consolidated sand, and for mean normal pressures lower than the cross-over point, the yield surface becomes the failure surface. This new failure surface is modelled well by the expression for the yield surface. Since the yield surface crosses the failure surface at a sharp angle, as explained in connection with Figure 9, a small, rather imperceptible 'bump' is created in the failure surface as it transitions from the normally consolidated region at high confining pressures to the overconsolidated region at lower confining pressures. For mean normal stresses higher than the cross-over point, the yield surface is encountered inside the failure surface, as shown in Figure 13.

\section{Behaviour of cemented soils}

The cementation between sand grains and in sandstone acts as bonds between the individual grains, preventing movement of the grains before the cementation is broken (Clough et al., 1981). This results in behaviour similar to the behaviour of overconsolidated soil, where an initial yield surface exists. According to Leroueil and Vaughan (1990), the initial yield surface is affected by the structure in the 
The role of cementation in the behaviour of cemented soils

Lade and Trads

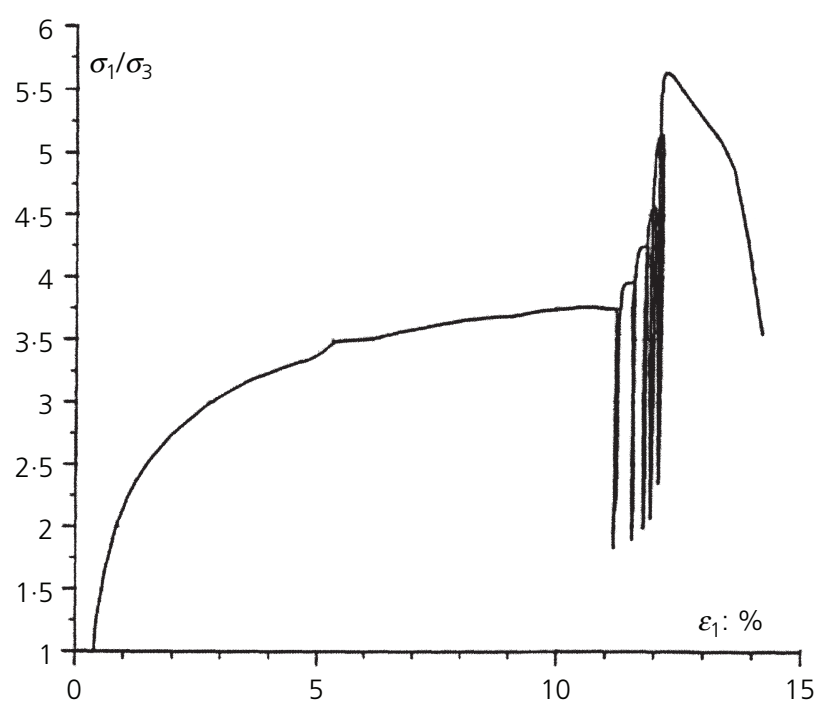

(a)

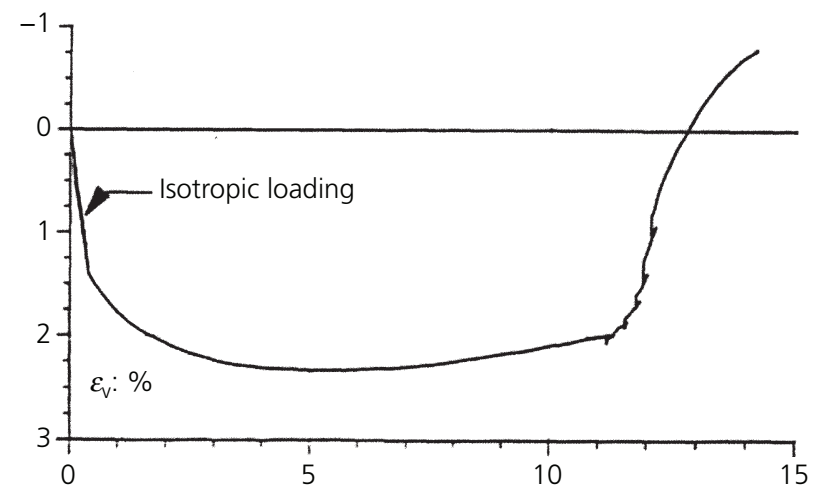

(b)

Figure 12. (a) Stress-ratio strain and (b) volume change behaviour from triaxial compression tests with decreasing mean normal stress on medium loose Santa Monica Beach sand

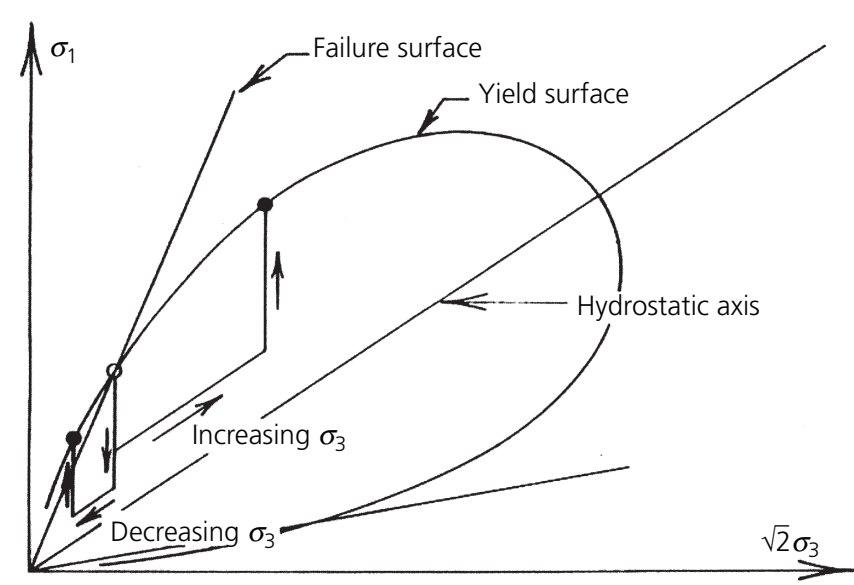

Figure 13. Schematic diagram showing the location of yield surface in hardening regime for sand presheared to peak failure followed by shearing at increased or decreased confining pressure material. Structure has also been identified in uncemented soil and can be caused by deposition of silica at particle contacts in sands; from cold welding at interparticle contacts under high pressure; from deposition of carbonates, hydroxides or organic matter from a solution; and from recrystallisation of minerals during weathering.

Different cementing agents have also been employed in research studies of the behaviour of artificially cemented soil. These cementing agents include Portland cement, lime, fly ash, gypsum, fired kaolin and calcite (Huang and Airey, 1993; Indraratna et al., 1995; Ismail et al., 2002; Lo et al., 2003; Toll and Malandraki, 1993). Depending on where the cementing agent is located, at the grain contacts and in the voids, and how much the cementing agent fills in the voids, it will contribute differently to the strength and hydraulic conductivity of the material. Thus, gypsum and calcite result in brittle yield, and the degree of brittleness increases significantly with the amount of cement (Ismail et al., 2002). In comparison, Portland cement produces the highest strength, more dilation and more ductile yielding behaviour than the other two cementing agents. However, increasing the amount of Portland cement would eventually result in brittle yielding.

In cemented soils, the structure can further arise from interlocking fabric (Clough et al., 1981; Cuccovillo and Coop, 1999). Furthermore, the ratio between the strength of the grains and the strength of the cementation results in different structure (Cuccovillo and Coop, 1999). As the effects of cementation and structure are similar and difficult to distinguish in weakly cemented soil (Leroueil and Vaughan, 1990), the behaviour of weakly cemented soils described in the following sections might arise from either, and no distinction is made.

To understand the behaviour of cemented soils, it is most important to determine the region in which the cementation influences the stressstrain behaviour before the cementation degrades and plastic yielding occurs. Fracture or failure in this region has often been expressed in terms of empirical strain-based criteria. Initiation of fracture occurs when principal strain magnitudes reach critical values. From experimentation, it appears that the region of elastic behaviour created by cementation has a shape similar to that of a yield surface in sand formed by preshearing or overconsolidation, as shown in Figure 13. Inside this yield surface for overconsolidated sand, the strains are very small and elastic in nature, as seen in Figure 12 for medium loose Santa Monica beach sand. This diagram also shows that after the stress path reaches the yield surface again, large plastic strains are produced and the rate of dilation is much higher than observed for the sand in the normally consolidated region. Similar behaviour is observed for cemented soils, as discussed below.

\section{Conceptual model for 3D behaviour of cemented soils}

With background in the behaviour of overconsolidated sand, a conceptual model for the behaviour of cemented sands emerges. This conceptual model has been created from synthesis of observations of the behaviour of cemented soils, mortar and sandstone. Results of drained tests are presented in support of the model, and additional 
The role of cementation in the behaviour

of cemented soils

Lade and Trads experiments have been performed on cemented soil (mortar) to test some of the salient features of the model.

\section{Cementation yield surface}

The presence of cracks and fissures on the microscale affects the overall strength of a porous rock. An increase in the overall stress magnitude also causes higher local stresses. If the local stress exceeds the local strength, cracks occur, grow and interact. If the orientation or the magnitude of the principal stresses changes, new damage may occur. Apart from the stress magnitude and orientation, the amount of new damage depends on the damage that has previously been induced (Kranz, 1983).

The permanent damage results in plastic deformation and can be used to determine the cementation yield surface. Pestman and Van Munster (1996), Wong et al. (1997) and David et al. (1998) measured acoustic emissions to determine the bond breakage in sandstones and cemented sand. They found a significant increase in acoustic emission when the cementation starts breaking. The approximate shape of this damage or destructuration surface is shown in the $p-q$ stress space in Figure 14. It is similar to that suggested by Gens and Nova (1993).

The method described for the determination of the cementation yield surface was used by David et al. (1998) to determine the relation between the cement content and the size of the cementation yield surface. They found that by increasing the cement content, the yield surface increased in size, shifting the brittle-to-ductile transition towards higher pressures.

The yield surface separates elastic behaviour from elastoplastic behaviour, and the elasticity experienced inside the yield surface is often considered linearly elastic. Therefore, the deviation from a linear stress-strain relation can also be used to determine the yield surface (e.g. Airey, 1993; Leroueil and Vaughan, 1990). This is shown in Figure 15 based on a procedure described by Airey (1993) where both axial and radial strains are used.

Post-yielding behaviour (often referred to as cataclastic flow) is dominated by grain crushing and pore collapse (Wong et al.,

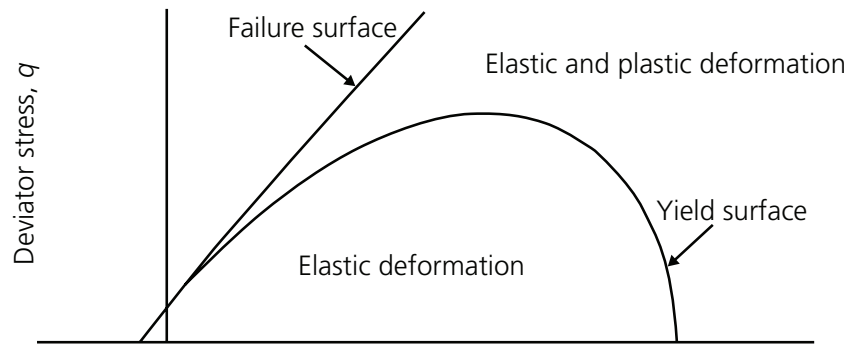

Mean stress, $p$

Figure 14. Shape of yield surface determined from acoustic emission (after Airey (1993))

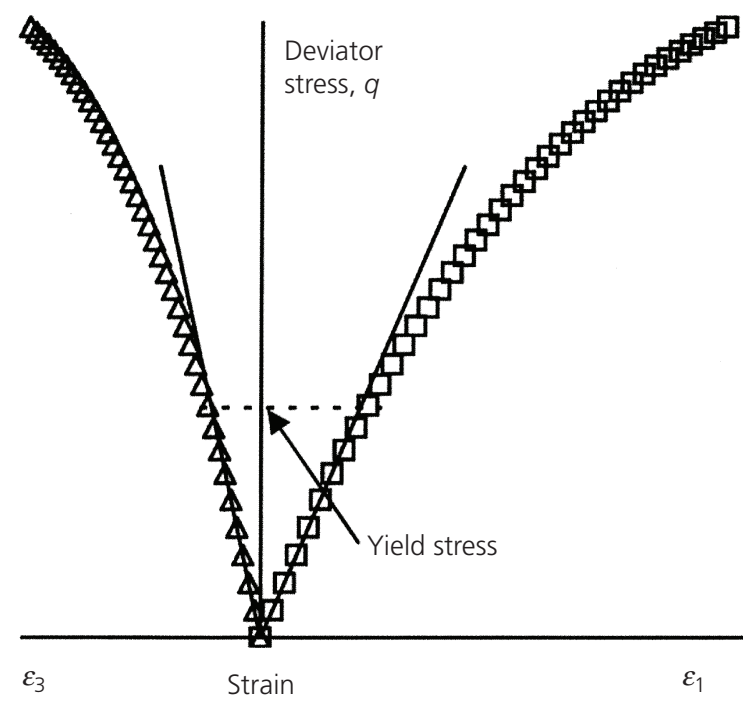

Figure 15. Determination of plastic yielding from deviation from linear behaviour (after Airey (1993))

1997). According to Pestman and Van Munster (1996), the yield surface expands and provides the state of crushing corresponding to the state of stress to which the material has previously been subjected. The state of crushing determines the elastic modulus for the material, and this becomes smaller with increasing amounts of crushing.

\section{Elastic behaviour inside the cementation yield surface}

The elastic behaviour inside the cementation surface varies with the degree of cementation (Baig et al., 1997; Clough et al., 1981; Huang and Airey, 1998; Schnaid et al., 2001; Sharma and Fahey, 2003). Figure 16 summarises their findings schematically. The relation between the elastic modulus and the stress is shown for increasing degree of cementation. The elastic modulus increases as the stress is increased, and increasing the degree of cementation results in higher elastic modulus as well. Furthermore, the elastic modulus becomes less dependent on the confining pressure with increased cementation. Baig et al. (1997) concluded that the effect 
Geotechnical Research

Volume 1 Issue 4
The role of cementation in the behaviour

of cemented soils

Lade and Trads of confining pressure was less significant at small strains, rendering the effect of confining pressure negligible for the dynamic properties of cemented soil.

The elastic behaviour during cementation bond breakage has been studied under different loading conditions: Huang and Airey (1998) determined the static bulk modulus during isotropic loading; Fernandez and Santamarina (2001) determined the dynamic elastic modulus during isotropic loading; Sharma and Fahey (2003) investigated the degradation of stiffness during triaxial compression; and Yun and Santamarina (2005) examined the dynamic stiffness during $K_{0}$ loading. The general evolution of elastic modulus during breakage of the bonds is also shown in Figure 16. As the bonds start breaking, a decrease in elastic modulus is experienced. As the elastic modulus of the cemented soil reaches that of the uncemented soil, the elastic modulus starts increasing, eventually becoming identical to that for the uncemented soil. If the initial degree of cementation is increased, the stress required to break the cementation increases, and the subsequent drop in elastic modulus diminishes. The dynamic elastic modulus has been found to not converge towards the elastic modulus of the uncemented soil as easily as the static elastic modulus.

The elastic modulus in tension and compression has been found to be similar. For example, Talesnick et al. (2000) found the elastic modulus in tension and in compression to be approximately the same in sandstone and cemented sand. Liao et al. (1997) found argillite to be stiffer in tension than in compression. This was attributed to closure of microfissures in compression, indicating that stress history causes different elastic moduli in compression and tension. This is demonstrated in Figure 17, where the stress-strain relation

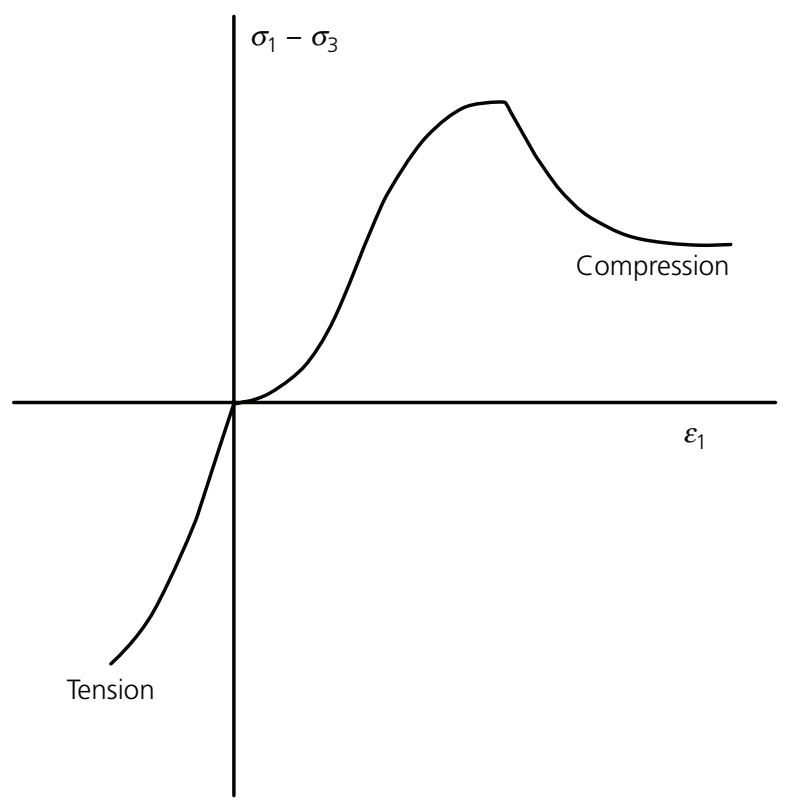

Figure 17. Closure of fissures results in initial lower Young's modulus in compression than in tension (after Liao et al. (1997)) in compression and tension is shown. In compression, Young's modulus increases as the fissures close and eventually becomes equal to Young's modulus in tension. In tension, the elastic modulus remains constant.

Trads and Lade (2014) performed torsion shear tests on large hollow cylinder specimens of cemented sand in which larger and larger areas inside the cementation yield surface were circumscribed by stress paths consisting of changes in normal and shear stresses. They found the material to be elastic in the sense that no residual strains remained after each cycle. Figure 18 shows the stress paths and the resulting strains.

\section{Failure surface}

The yield and failure surfaces for a cemented soil are shown in Figure 19. This diagram shows the triaxial plane of the principal stress space with the hydrostatic axis pointing up to the right. Because of the tensile strength caused by cementation, the failure surface initiates in the part of the stress space where the stresses are negative and it opens up in the outward direction of the hydrostatic axis. The teardrop-shaped yield surface initiates at the same point as the failure surface and extends into the positive stress space where it crosses the hydrostatic axis. Note that the yield surface bends backwards towards the hydrostatic axis corresponding to lower values of $q$ before it crosses the failure surface. The uniaxial compressive strength corresponds to a point on the yield surface, which is outside or coincides with the failure surface at this point. The stress-strain curve in the uniaxial compression test indicates that yielding and failure coincide, and softening follows immediately after failure.

The tensile strength is instrumental in determining the location of the failure surface in the region of low stresses. It is important to model the failure surface correctly in this region because this is where tensile fracture occurs, and the material exhibits very brittle behaviour at low stresses. The locations of the plastic yield points for isotropic and $K_{0}$ compression are also indicated in Figure 19.

The behaviour is elastic inside the initial plastic yield surface (Trads and Lade, 2014), as indicated in Figure 20. Plastic behaviour is encountered as the stress point moves beyond the yield surface, and softening will occur immediately in the region where the yield surface is outside the failure surface. Thus, in this region, the yield surface is also the failure surface. In fact, in the region where the yield surface becomes the failure surface, the peak failure is caused by and is immediately followed by strain localisation and shear banding. This is in complete agreement with the effects of overconsolidation, as encountered in sands and clays (Lade and Prabucki, 1995).

The softening is more pronounced at lower confining pressures, where shear banding follows the peak. This is because the plastic yield surface crosses the failure surface and the yield surface becomes the failure surface at lower confining pressures, as indicated in Figure 20(a). In the region of larger mean normal 

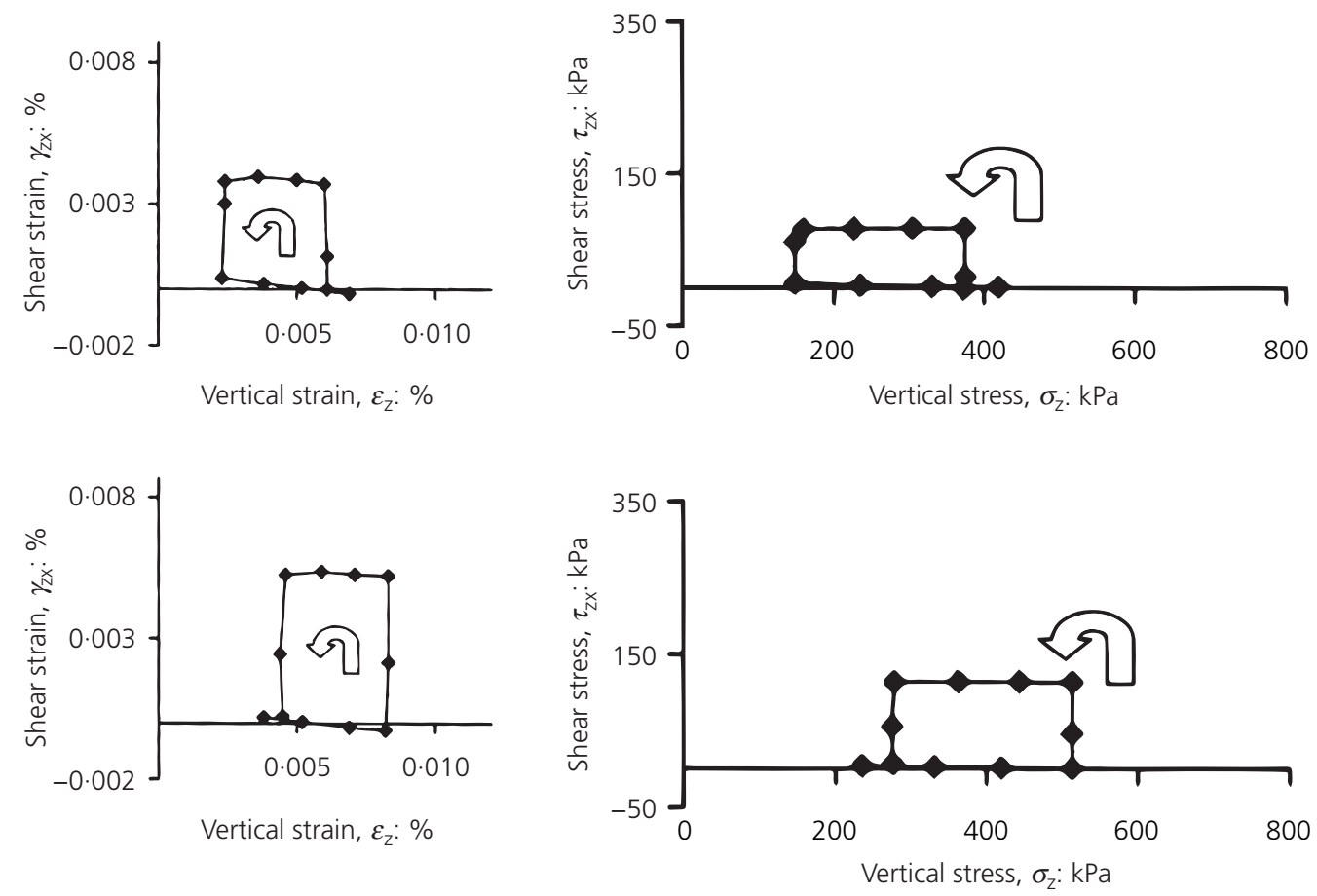

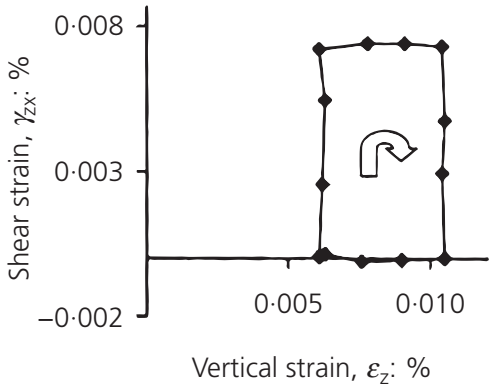

(a)

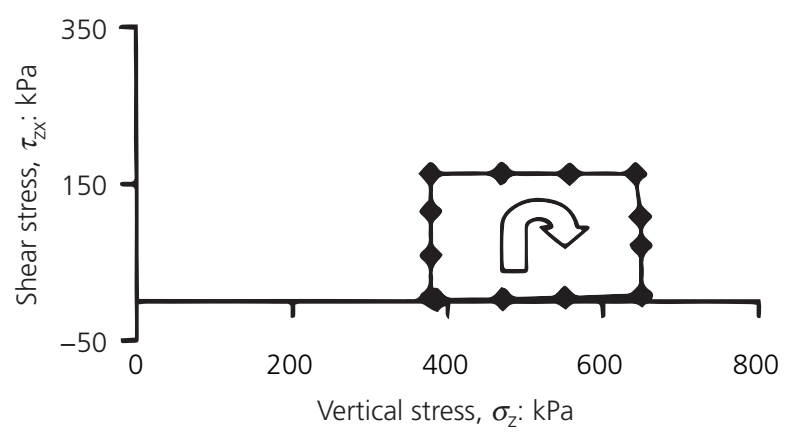

(b)

Figure 18. Diagrams of measured strains in torsion shear test on cemented sand for three sequential stress loops, each indicating elastic response inside the cementation yield surface (from Trads and Lade, 2014)

stresses, where the yield surface is inside the failure surface, the stress-strain behaviour that exhibits work hardening before failure is encountered at larger strains. In this region, the cementation continuously degrades until it is completely broken at large strains. As the stresses reach further up, smooth peak failure is encountered with smooth transition into softening. The corresponding stressstrain behaviour is shown in Figure 20(b).

\section{Effect of intermediate principal stress}

The intermediate principal stress has a pronounced effect on the stress-strain and strength behaviour of all frictional materials. While the Mohr-Coulomb failure criterion is the classic failure criterion for frictional materials, it predicts that the intermediate principal stress has no effect on the strength of frictional materials. The von Mises criterion, on the other hand, predicts a too large and very inaccurate influence of the intermediate principal stress, even when modified as in Drucker and Prager (1952).

Many experiments have been performed on various types of rock as well as on concrete, and they all appear to produce similar and comparable results, as reviewed by Lade (1993). The experimentally observed failure surfaces, indicated in Figure 21, are shaped as an asymmetric bullet with the pointed apex located on the negative side of the hydrostatic axis, and with a cross-sectional shape in the octahedral plane that is triangular with smoothly rounded edges. The curved failure surface is concave towards the hydrostatic axis. 
The role of cementation in the behaviour of cemented soils

Lade and Trads

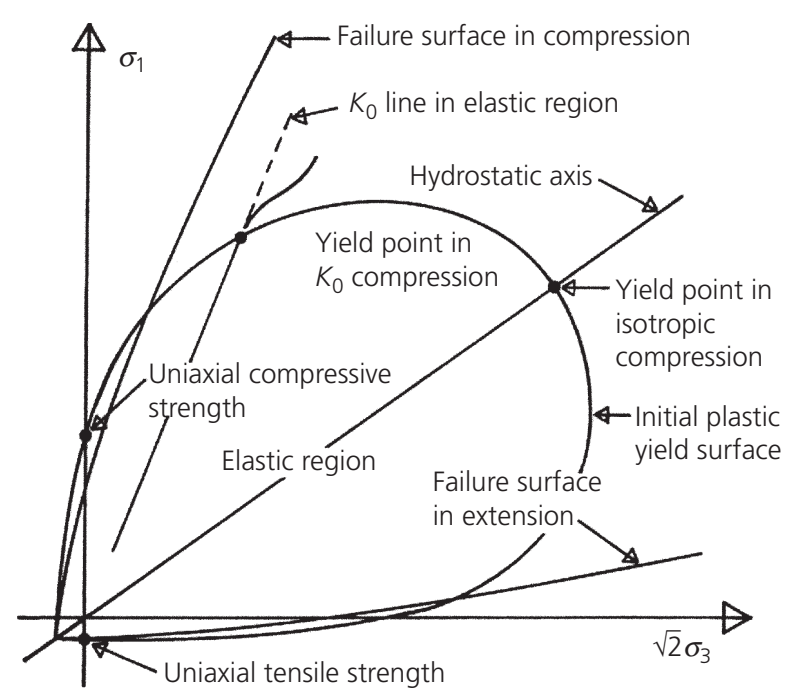

Figure 19. Conceptual model for three-dimensional conditions shown in triaxial plane

Shear banding in the hardening regime of the stress-strain relations for high confining pressures where the cementation has been broken may modify this shape in the midrange of $b$ values, where $b=\left(\sigma_{2}-\sigma_{3}\right) /\left(\sigma_{1}-\sigma_{3}\right)$.

The effect of the intermediate principal stress on the strength of sandstone and mudstone was also examined by Lee et al. (1999, 2002). In both materials, the effect of the intermediate principal stress is similar to that shown in Figure 21. This is also in agreement with tests performed by Reddy and Saxena (1993) on artificially cemented sand. The effect of the intermediate principal stress was also noted by Al-Ajmi and Zimmerman (2005) after compiling triaxial strength data of eight different porous rocks.
Most frictional materials with cementation, such as cemented soils, concrete and rock, follow the pattern of behaviour described above. Experiments are presented below in support of the conceptual model described above.

\section{Isotropic compression}

The influence of cementation on the volumetric behaviour during isotropic compression is shown in Figure 22. Until yielding, the cemented soil behaves elastically, and the degree of cementation determines the location of the yield point in comparison with the intrinsic compression line. In most cemented soils, yielding takes place beyond the intrinsic compression line. Lagioia and Nova (1995) observed temporarily unstable behaviour in a straincontrolled isotropic compression test, corresponding to a reduction in the stress right after yielding. After yielding, the cementation breaks and the soil eventually returns to the behaviour of the uncemented soil. Examples of behaviour during isotropic compression can be found in, for example, Coop and Atkinson (1993), Leroueil and Vaughan (1990) and Cuss et al. (2003).

In some natural soils, the initial behaviour during isotropic compression is softer due to closure of preexisting cracks and fissures (e.g. Cuss et al., 2003). This was discussed in connection with Figure 17.

\section{$K_{0}$ compression}

The behaviour of sandstone during $K_{0}$ loading is similar to the behaviour during isotropic compression. The loading begins elastically until yielding, where the cementation starts breaking and the soil eventually returns to the intrinsic compression line of the sand. This is illustrated in Figure 23(a). Because of the difference in boundary conditions, compared with the isotropic compression test, the stress path for $K_{0}$ compression is not predetermined. According to Nova et al. (2003), the transition from elastic to plastic behaviour

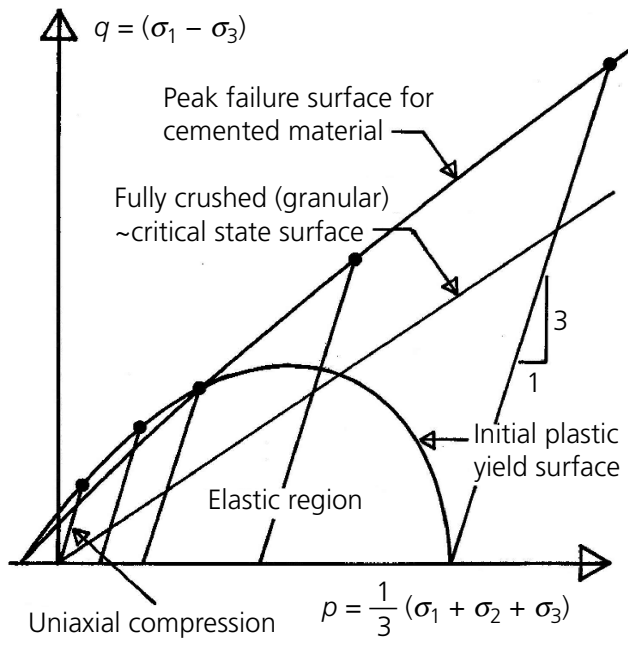

Uniaxial compression

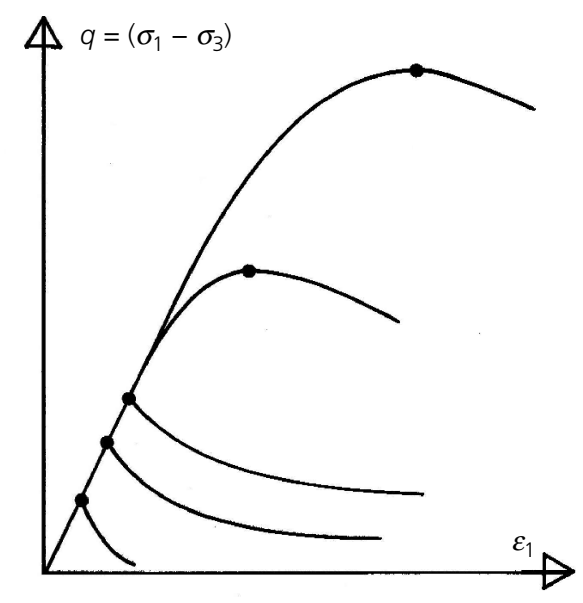

Figure 20. Conceptual model for stress-strain behaviour of cemented material in triaxial compression tests 


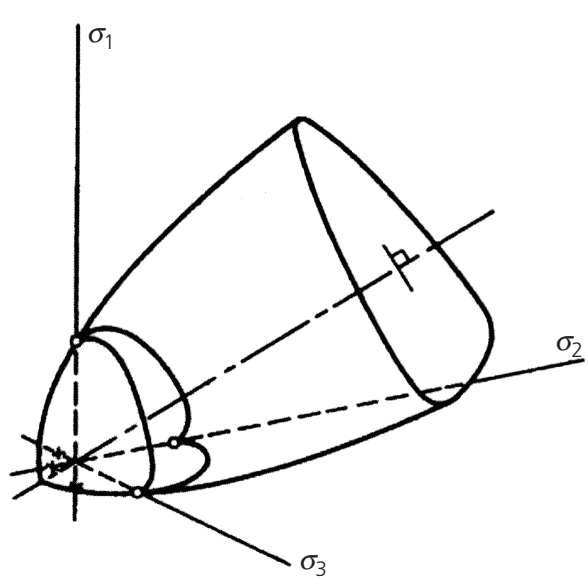

(a)

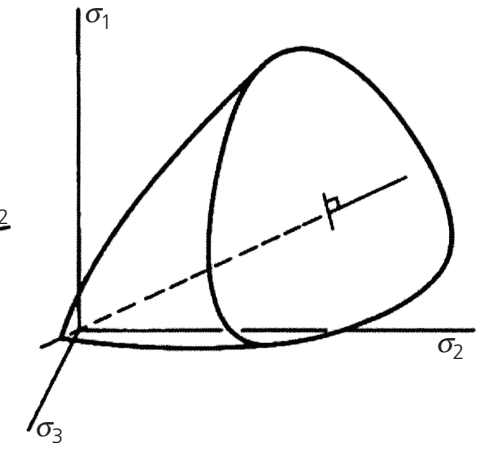

(b)

Figure 21. Three-dimensional failure surface produced from experimental evidence and viewed (a) from the side to show curved envelope in triaxial plane and biaxial planes and (b) from the end to show smoothly rounded triangular shape in octahedral plane

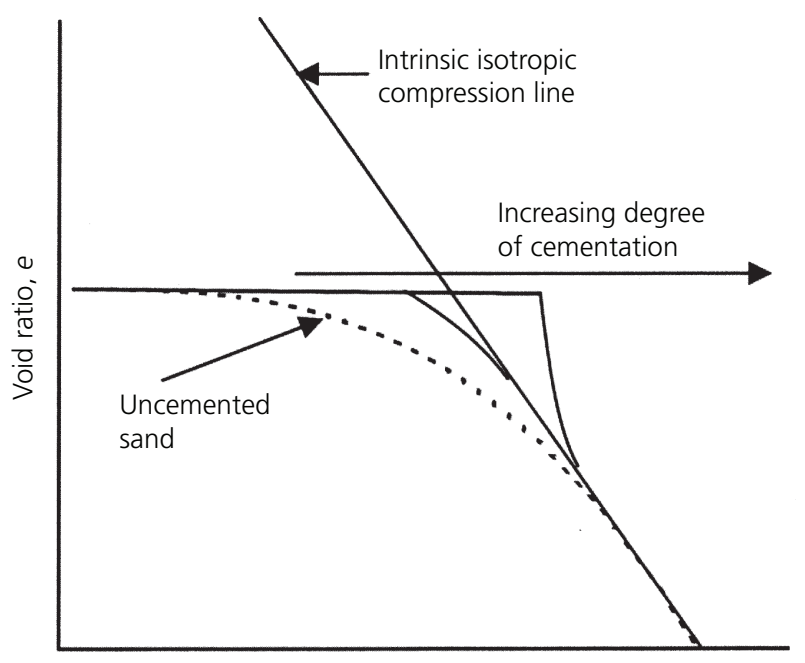

$\ln \sigma_{\mathrm{c}}^{\prime}$

Figure 22. Schematic representation of the influence of cementation during isotropic compression (after Cuccovillo and Coop (1999))

follows the yield surface, if no bond degradation takes place. The degree of cementation influences the transition from elastic to plastic behaviour, as illustrated in Figure 23(b). Examples of stress paths from $K_{0}$ loading can be found in, for instance, Leroueil and Vaughan (1990), Coop and Atkinson (1993) and Lagioia and Nova (1995).

\section{Stress-strain and volume change behaviour}

Coop and Atkinson (1993) and Cuccovillo and Coop (1999) identified two types of behaviour of cemented soil, based on the degree of cementation. These idealised behaviours are shown in Figures 24 and 25. Figure 24(a) shows the location of the initial cementation yield surface and the critical state line for strongly cemented soil, with indication of three stress paths for triaxial compression. Figure 24(b) shows the normalised (with respect to $q / p$ ) stress-strain response corresponding to the three stress paths in Figure 24(a). Similarly, the yield surface, the critical state line, the failure surface and the stress paths for weakly cemented soil are shown in Figure 25(a). The corresponding normalised stress-strain response is shown in Figure 25(b). Note that Figures 24(a) and 25(a) are shown with almost similar size of the cementation yield surface. If shown on the same scales, the cementation yield surface in Figure 24(a) would be significantly larger than the yield surface in Figure 25(a).

In the strongly cemented soil, the yield surface increases the peak strength at low confining pressures resulting in elastic behaviour until failure. As the confining pressure increases, the yield surface is reached before the critical state line, resulting in first elastic then elastoplastic behaviour. At high confining pressure, only elastoplastic behaviour is observed.

In the weakly cemented soil, the stress-strain behaviour is similar to the strongly cemented soil at low confining pressures, where the behaviour is elastic until failure, and at high confining pressures, where only elastoplastic behaviour is experienced. In the intermediate range, two other types of stress-strain behaviour are observed: one starting inside the cementation yield surface and one starting outside. Both experience increased peak strength with subsequent reduction to the critical state line.

Wu et al. (2000) determined the onset of dilatancy inside the cementation yield surface for two different sandstones and found the onset of dilatancy to vary linearly with confining pressure. The 
Geotechnical Research

Volume 1 Issue 4
The role of cementation in the behaviour

of cemented soils

Lade and Trads

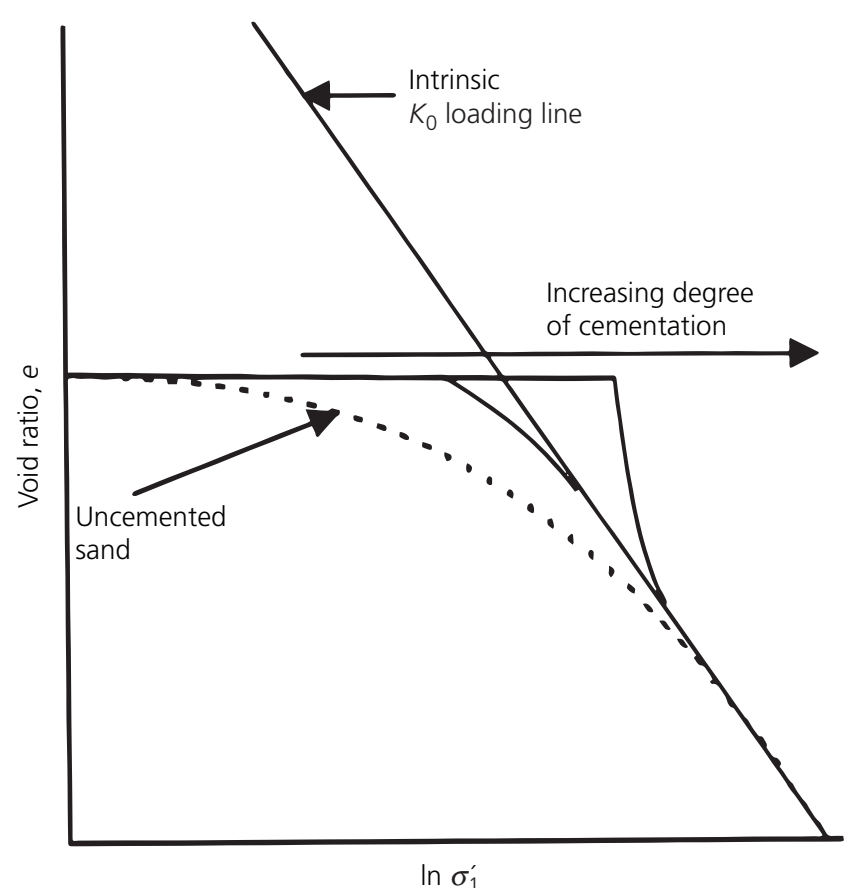

(a)

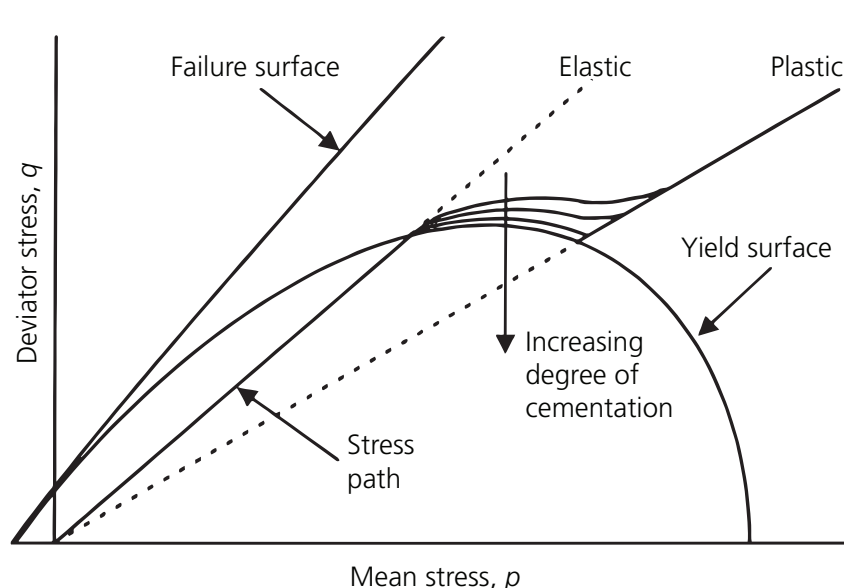

(b)

Figure 23. (a) Schematic representation of the influence of cementation during $K_{0}$ loading and (b) stress paths followed during $K_{0}$ loading (after Coop and Atkinson (1993), Cuccovillo and Coop (1999))

best-fit line was parallel-shifted to intersect the $q$-axis, resulting in increased contraction (compared with sand) before the onset of dilatancy. This is in agreement with findings by, for example, Lade and Overton (1989), who found delayed onset of dilatancy with increased degree of cementation. Furthermore, the rate of dilatancy experienced was higher in cemented sand than in uncemented sand. As the confining pressure increases, the rate of dilation decreases, and at high confining pressures, only contractive behaviour is observed.

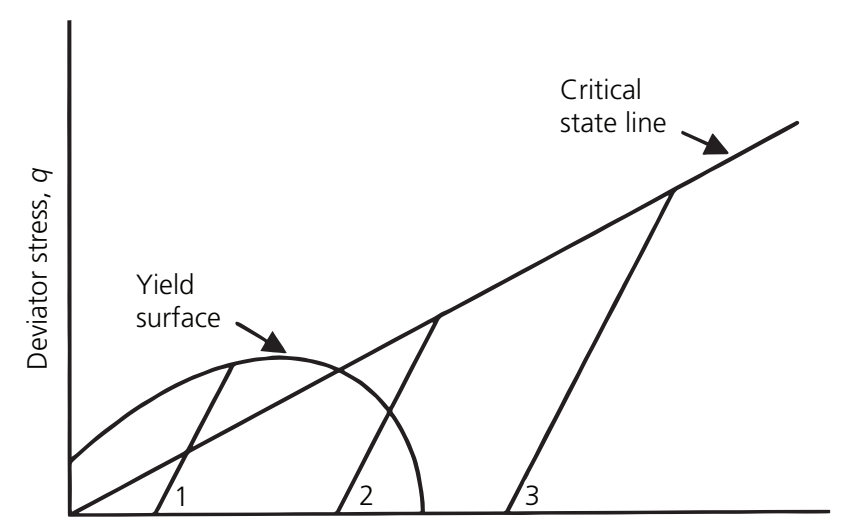

Mean stress, $p$

(a)

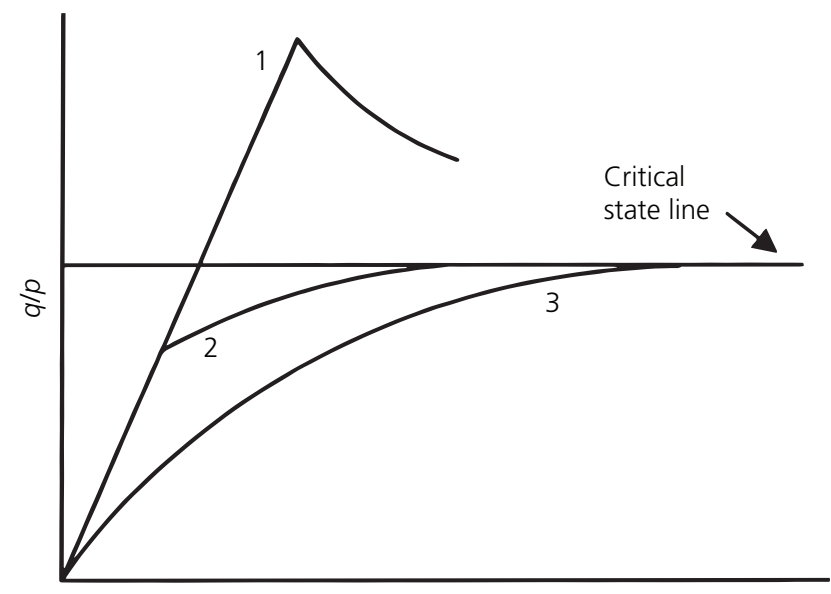

Major principal strain, $\varepsilon_{1}$

(b)

Figure 24. Idealized behaviour of strongly cemented soil (after Coop and Atkinson (1993)) 
The role of cementation in the behaviour

of cemented soils

Lade and Trads

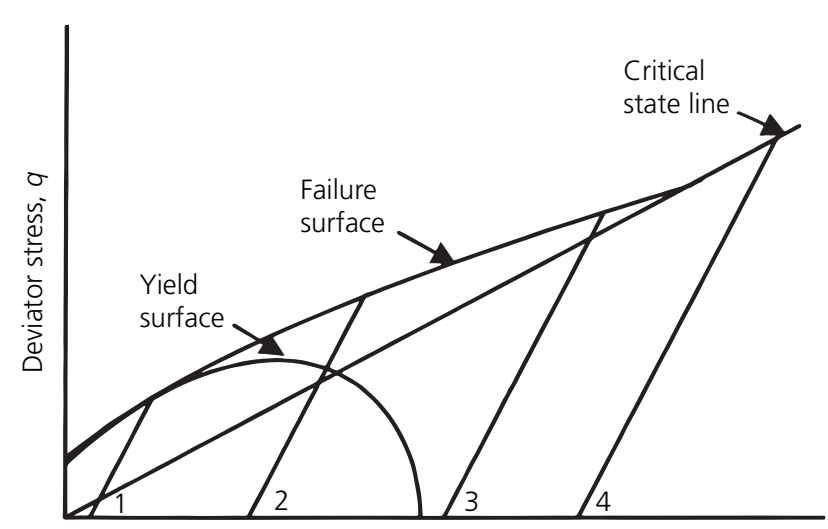

Mean stress, $p$

(a)

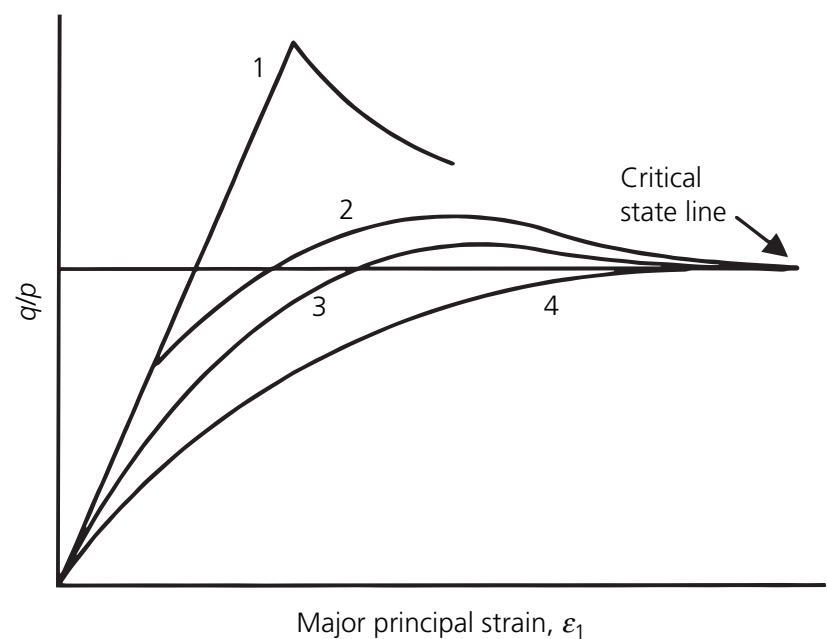

(b)

Figure 25. Idealized behaviour of weakly cemented soil (after Cuccovillo and Coop (1999))

\section{Controlling factors}

The three most important factors that control the stress-strain and volume change behaviour of cemented sands are the effective confining pressure, the void ratio, and the amount of cementation. During unconfined conditions, the cemented soil behaves as a brittle material and the strength is controlled primarily by the void ratio and the degree of cementation. Figure 26 shows the conceptual variation of compressive and tensile strength as a function of void ratio and cementation, based on findings by Huang and Airey (1998) and Consoli et al. (2007). An increase in the cementation results in an increase in the strength. Increasing the void ratio decreases the strength. At low void ratios, an increase in the degree of cementation results in a higher increase in strength than at high void ratios. This has been attributed to the particles being closer together at low void ratios causing the cementing agent to be more effective. At higher void ratios, the cementing agent is located at the grain contacts, thus having less of a binding effect on the grains and resulting in a lower increase in strength.

The unconfined test indicates essentially linear behaviour until plastic yielding initiates at the failure surface, after which the volumetric dilation becomes very strong. This behaviour is similar to that observed in the overconsolidated sand in Figure 12, in which very small strains occurred before the yield surface was reached, and after which the rate of dilation became much higher than that in the normally consolidated sand. Thus, the maximum rate of dilation is obtained after the peak strength has been exceeded and while the cementation is breaking up. The strength is therefore not tied to the rate of dilation as it is for sand, but is determined by the amount of cementation. Once the cementation is beginning to break up, the stress-strain curves and the volumetric strain curves begin to resemble those obtained for sands with increasing contraction at higher confining pressures.

Lade and Overton (1989) studied the effect of cementation and confining pressure in triaxial compression tests on granular material

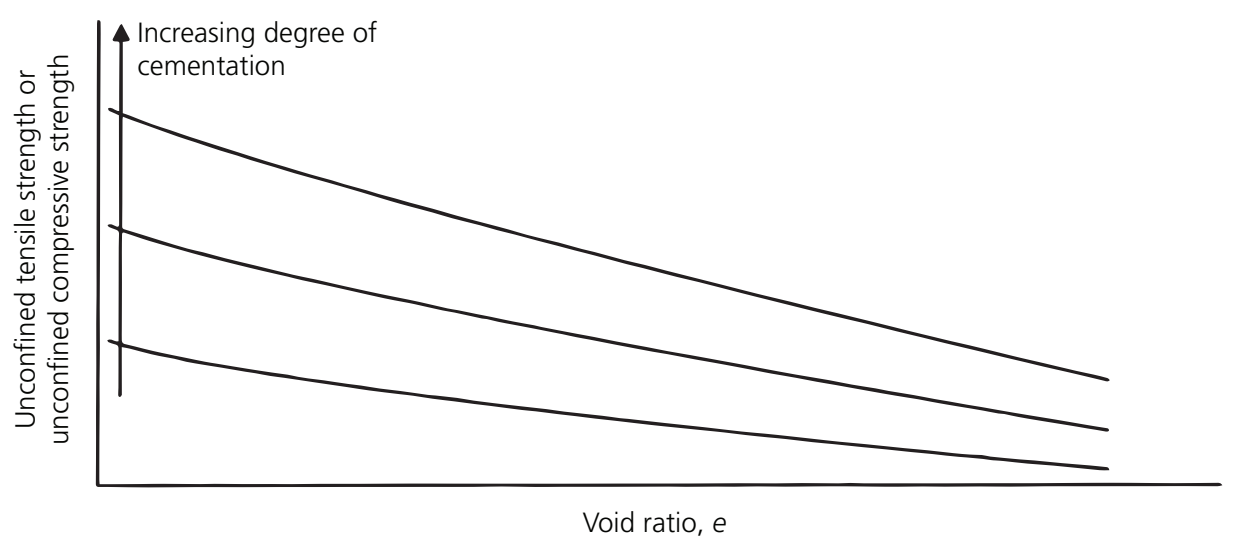

Figure 26. Relation between unconfined compressive/tensile strength and void ratio with degree of cementation 
Geotechnical Research

Volume 1 Issue 4
The role of cementation in the behaviour

of cemented soils

Lade and Trads with the same grain size curve, the same water/cement ratio, and the same density. The cement contents were $0 \%$ (compacted soil), $6 \%$ (soil-cement) and 12\% (mortar). According to Lade and Overton (1989), the effect of cementation on the failure at low confining pressures is an increase in both friction angle and cohesion. This was attributed to cementation as well as an increase in dilation. This is in agreement with later studies by Schnaid et al. (2001), who found that the effect of cementation at low confining pressures is to increase both friction angle and cohesion. Figure 27 shows the effect of confining pressure on the results of drained triaxial compression tests on the soil-cement. The stress-strain curves are almost linear within the range of stresses of intact cementation, and the volume changes are contractive and tend to follow the same relation until the cementation begins to disintegrate and plastic yielding is initiated. After the yield surface has been exceeded, the stress-strain relations become highly non-linear, and their shapes change considerably over the range of confining pressures employed in the tests.

In the intermediate range of confining pressures, the cementation breaks, and the effect of cementation was interpreted by Lade and Overton (1989) as a parallel shift of the failure surface equal to the cohesion. This corresponds to the findings by Clough et al. (1981) at low confining pressures.

Under high confining pressures, the soil behaviour becomes ductile, with a substantial amount of plastic deformation prior to failure. Under these conditions, the effect of the cementation is
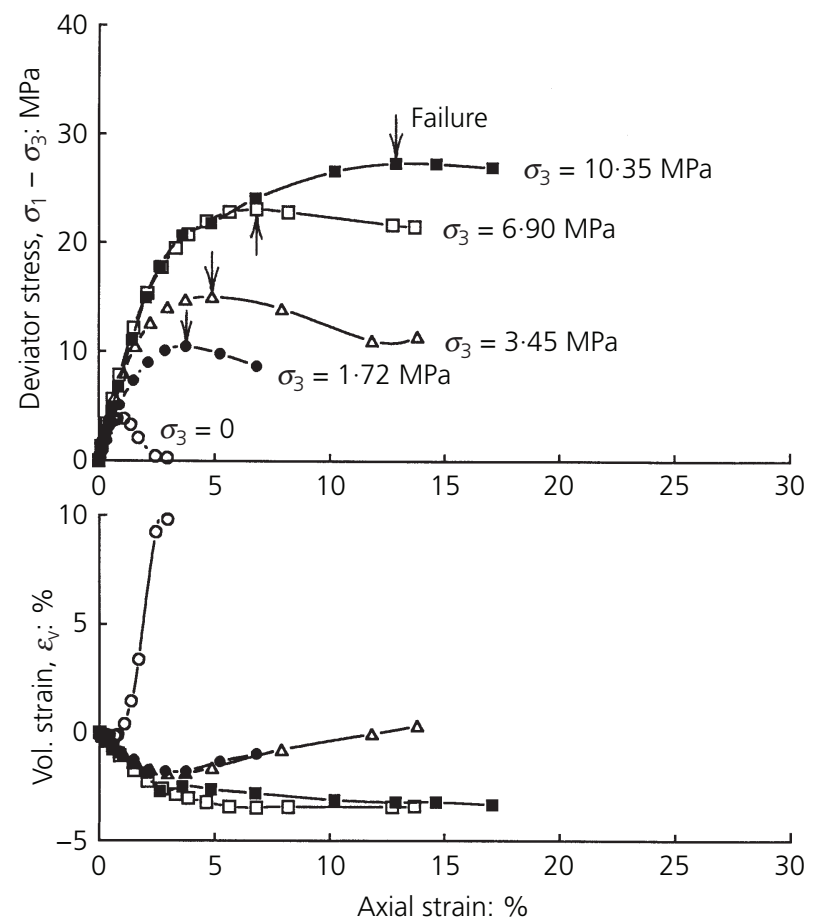

Figure 27. Stress-strain and volumetric strain curves for soilcement with 6\% cement (after Lade and Overton (1989)) insignificant and only the friction angle is slightly increased by the initial cementation (Coop and Atkinson, 1993). Tests by Lade and Overton (1989) indicated that the strength at high confining pressures of a material with lower degree of cementation could surpass the strength of the same material but with higher degree of cementation. This is shown in Figure 28, and was explained by the material with the lower degree of cementation experiencing an increased compression during application of the higher confining pressure, thereby creating additional frictional strength.

Using the method of determining the point of yielding advocated by Airey (1993), that is, the points where the stress-strain and volume change curves deviate from linearity, the results for soil-cement produce the cementation yield surface and the failure surface shown in Figure 29. This corresponds to the behaviour for weakly cemented sand shown in Figure 25, as proposed by Cuccovillo and Coop (1999).

After the bonds are broken, the soil does not necessarily return to the behaviour of the similar uncemented soil (Clough et al., 1981). This is due to lumps of cemented material acting as larger particles. However, Reddy and Saxena (1993) found the residual strength of an artificially cemented soil to be independent of the initial degree of cementation. This was experienced for triaxial compression tests at both low and high confining pressures.

It should be noted that the effective cohesion created by the cementation and the shear strength generated by the friction and the confining pressure are not mobilised at the same time. This is because the cementation is broken at very small strains (1-2\% axial strain in the soil-cement and the mortar), whereas mobilisation of the frictional component of the shear strength may require considerable straining. Thus, the two components are not mobilised simultaneously and therefore do not sum up to produce the total strength. Rather, the cementation is mobilised first, and after fracture is initiated, the frictional component is being engaged as straining continues. The stress-strain curves may consequently show an initial peak followed by strain softening and renewed strength increase to a second peak. This second peak may be higher or lower than the peak caused by cementation.

Figure 30 shows the effect of increasing the amount of cementation to $12 \%$ while maintaining the density at the same constant value as for the soil-cement shown in Figure 27. However, the stiffness is greater, the strengths are higher and the yield points are also located at higher stresses. Once the cementation is broken, the post-peak behaviour of the mortar shows faster strain softening than that obtained in the soil-cement. This is likely because the two cemented soils aspire to the same common residual strength line obtained after large strains and complete breakdown of cementation at which point the material is fully damaged and essentially behaves as sand.

\section{Volume changes}

Volume changes during shearing depend mostly on the confining pressure and the porosity of the material. Both contraction and 


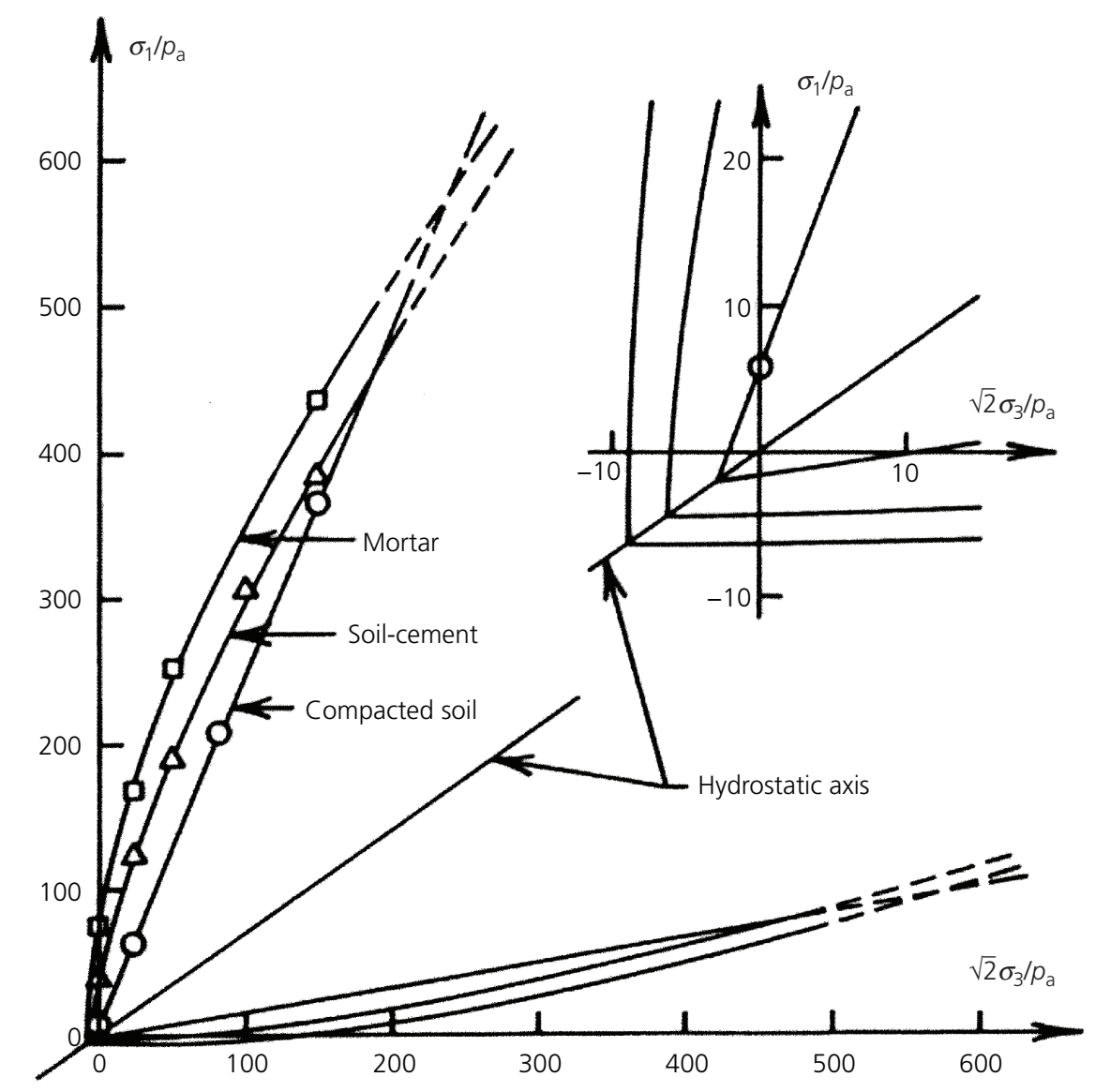

Figure 28. Comparison of failure surfaces for experimental results for compacted soil with $0 \%$ cement, soil-cement with $6 \%$ cement and mortar with 12\% cement (after Lade and Overton (1989))

dilation are encountered in cemented soils, with the contraction occurring at high confining pressures and high porosities, and dilation occurring closer to failure in cemented soils with low porosity and at lower confining pressures. The volume changes are elastic in the cemented region, and they are contractive near the hydrostatic axis, but they become dilative as the stresses reach into the plastic regime at higher stress ratios. The dilative volume changes are plastic in nature, and they are initiated only after the cemented region has been exceeded and the plastic yield surface has been activated. This occurs well inside the failure surface in the region of larger stresses where the plastic yield surface is inside the failure surface. In the region of lower stresses, where the yield surface becomes the failure surface, the plastic dilative volumetric strains begin upon reaching the yield surface. Dilation plays an important role in the formation of shear bands. The tendency for dilation increases with increasing intermediate principal stress.

\section{Shear bands in cemented soils}

Shear bands are localised strains often 4-10 grain diameters wide, with further damage restricted to within approximately
$2 \mathrm{~mm}$ of the shear band (Cuss et al., 2003; El Bied et al., 2002). Scanning electron microscope images obtained by El Bied et al. (2002) show that tests performed under low confining pressure have a shear zone characterised by grain cracking with no grain crushing, while tests performed under high confining pressure have a shear zone characterised by grain crushing and pulverisation. The shear bands at low confining pressures experience an increase in porosity and are therefore often referred to as dilating shear bands, whereas those at high confining pressures experience a decrease in porosity and are sometimes referred to as contraction shear bands. According to Sulem and Ouffroukh (2006), both the dilating and contracting shear bands experience a reduction in permeability, with the reduction being more pronounced in the contracting shear bands. The shear bands are near-failure phenomena, and Ord et al. (1991) observed that in plane strain tests, the shear band initiates in the hardening regime, resulting in a reduced strength. The angle of the shear band has been found to decrease as the confining pressure increases (Bésuelle et al., 2000; El Bied et al., 2002). The angle of the shear band is here defined as the angle between the major principal stress and the normal to the shear band. 


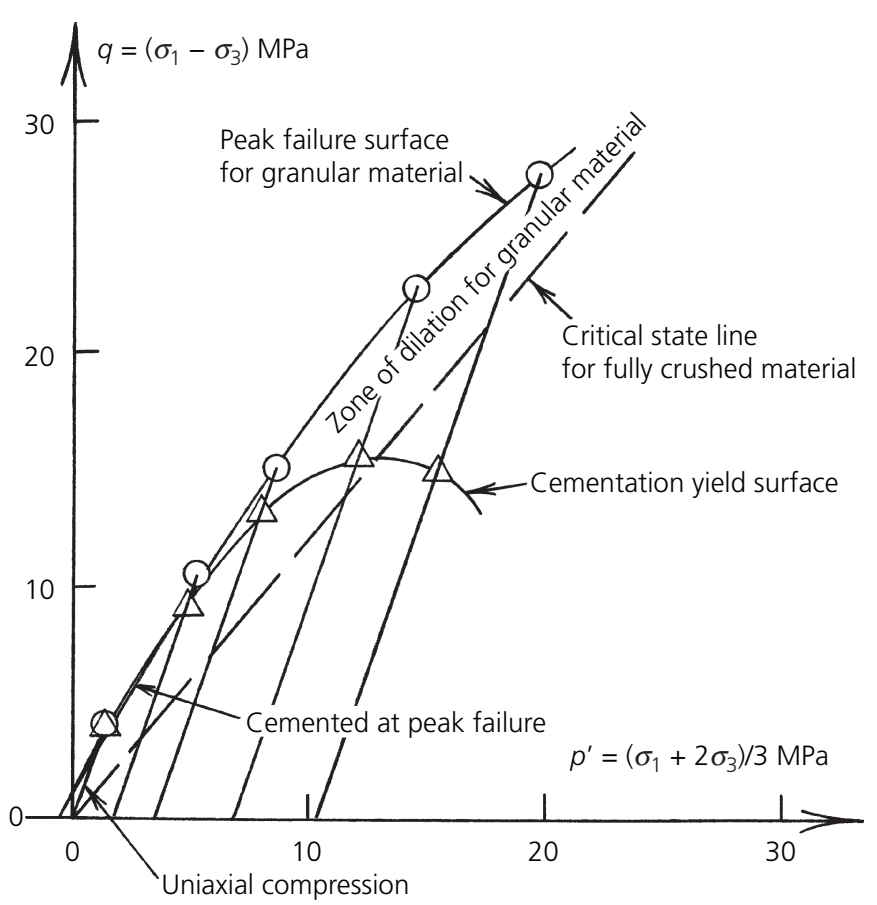

Figure 29. Cementation yield surface and failure surface for soilcement with $6 \%$ cement

Similar to the shear bands are the compaction bands observed by, for example, Olsson (1999), Klein et al. (2001) and Baud et al. (2004). Compaction bands are localised deformation with reduction in porosity and are approximately perpendicular to the major principal stress (angle of band equal to zero). They have been observed to form in the stress range around the cap of the cementation yield surface. According to Katsman and Aharonov (2006), compaction bands are likely to nucleate around heterogeneities in the rock properties, such as local variation in porosity or compressive strength.

\section{Effects of cementation history}

According to Rotta et al. (2003), cementation in natural sandstones takes place during several different loading-cementation histories, where the three major relations are as follows: (1) at the surface under no confining pressure, (2) at shallow depth after overconsolidation and (3) progressively with burial. The loading-cementation history affects the results of tests on natural sandstone.

To examine the effect of curing stress on isotropic yielding, Rotta et al. (2003) performed isotropic compression tests on specimens of artificially cemented sandstone. Two specimens with identical void ratio and degree of cementation were tested. Both were loaded to an isotropic pressure of $500 \mathrm{kPa}$. One was allowed to cure at that pressure while the other was unloaded until $50 \mathrm{kPa}$ and then cured. During further isotropic loading, the specimen cured under high confining pressure started yielding later than the specimen cured at low confining pressure. After yielding, the specimens behaved similarly, resulting in identical compression lines.
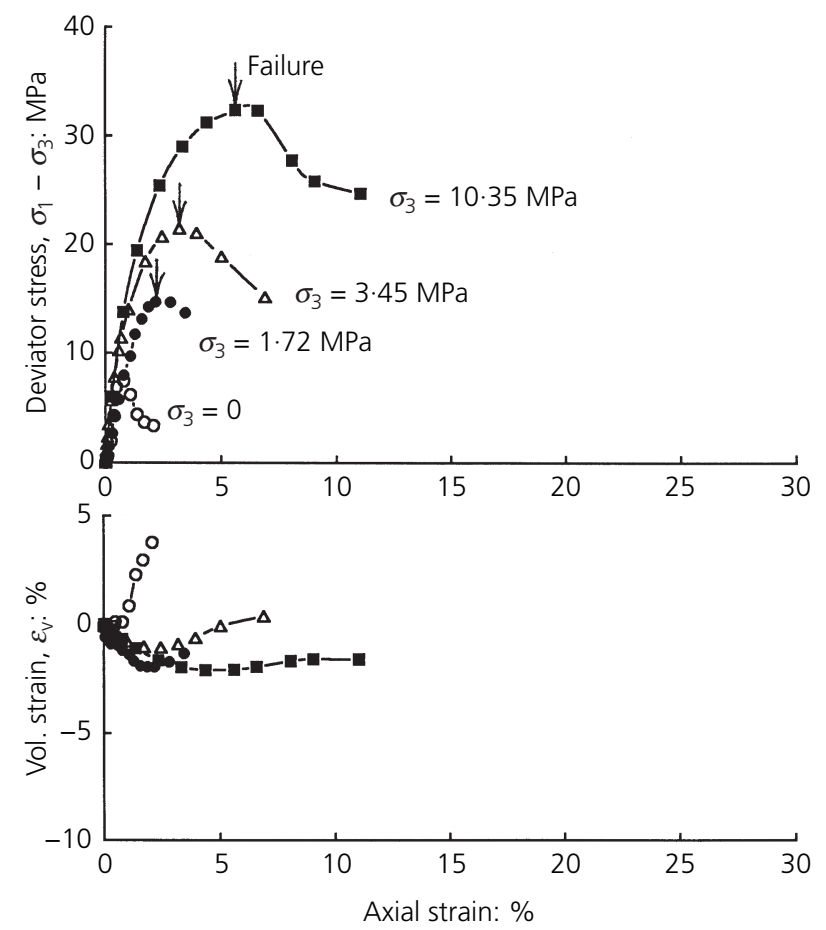

Figure 30. Stress-strain and volume change behaviour for mortar with 12\% cement (after Lade and Overton (1989))

To simulate the damage taking place when retrieving sandstone from in situ conditions and bringing it to the laboratory, Holt et al. (2000) performed oedometric tests on three different artificial sandstones, all cured under stress. They found that damage occurred during unloading from the simulated in situ stress. After reloading the sandstones to the curing stress, the bulk modulus and the elastic wave velocities were reduced. In weakly cemented sandstone, enough damage took place to break the bonds between the grains. As a result, the weakly cemented sandstone exhibited a reduction in void ratio during reloading, which was not found in the sandstones with stronger cementation. Fernandez and Santamarina (2001) showed experimentally that sandstone cemented under pressure could have the interparticle bonding damaged by unloading due to local tension on the cementing bonds.

\section{Conclusions}

The behaviour of cemented soils and sandstone has been reviewed based on experimental results presented in the literature and results obtained by the authors. The underlying stress-strain and strength behaviour of sand is first reviewed, and the effects of void ratio and confining pressure are emphasised. In cemented sands, the addition of cementing agents of various types and amounts is important for the location of the cementation yield surface. The stress-strain behaviour is elastic inside this surface, and it becomes elastoplastic outside where the cementation begins to break down. The cementation yield surface crosses the failure surface, and it 
becomes the failure surface at lower mean normal stresses. The cemented sand continues to break up as the stresses increase beyond the cementation yield surface, and it requires quite high stresses and strains to completely granulate the material.

All aspects of the behaviour of cemented soils may be modelled by elasticity and hardening plasticity theories for which the components of the failure surface, the plastic potential and the yield surface with the associated hardening law have already been expressed. Thus, the same framework as that used for modelling soils works well for cemented soils. Only a small change in the expression for the normal stresses before substituting into the expression for the failure and yield surfaces is required to account for the cohesion and the tensile strength observed near the stress origin. The parameter values consequently change, but the behaviour is otherwise similar to that of soils.

\section{Acknowledgements}

The research presented here was performed with support from the American Chemical Society Petroleum Research Fund under grant no. 40780-AC9. Grateful appreciation is expressed for this support.

\section{REFERENCES}

Airey DW (1993) Triaxial testing of naturally cemented carbonate soil. Journal of Geotechnical Engineering 119(9): 1379-1398.

Al-Ajmi AM and Zimmerman RW (2005) Relation between the Mogi and the Coulomb failure criteria. International Journal of Rock Mechanics and Mining Sciences 42(3): 431-439.

Arthur JRF, Dunstan T, Al-Ani QAJL and Assadi A (1977) Plastic deformation and failure in granular media. Géotechnique 27(1): 53-74.

Baig S, Picornell M and Nazarian S (1997) Low strain moduli of cemented sand. Journal of Geotechnical and Geoenvironmental Engineering 123(6): 540-545.

Baud P, Klein E and Wong T-F (2004) Compaction localization in porous sandstones: spatial evolution of damage and acoustic emission activity. Journal of Structural Geology 26: 603-624.

Bésuelle P, Desrues J and Raynaud S (2000) Experimental characterization of the localization phenomenon inside a Vosges sandstone in a triaxial cell. International Journal of Rock Mechanics and Mining Sciences 37(8): 1223-1237.

Bishop AW (1966) Strength of soils as engineering materials (Sixth Rankine Lecture). Géotechnique 16(2): 89-130.

Bopp PA and Lade PV (2005) Relative density effects on undrained sand behavior at high pressures. Soils and Foundations 45(1): 15-26.

Casagrande A (1936) Characteristics of cohesionless soils affecting the stability of slopes and earth fills. Journal of the Boston Society of Civil Engineers (Contributions to Soil Mechanics, 1935-1940, 257-276).

Clough GW, Sitar N and Bachus RC (1981) Cemented sand under static loading. Journal of the Geotechnical Engineering Division 107(GT6): 799-817.
Consoli NC, Foppa D, Festugato L and Heineck KS (2007) Key parameters for strength control of artificially cemented soils. Journal of Geotechnical and Geoenvironmental Engineering 133(2): 197-205.

Coop MR and Atkinson JH (1993) The mechanics of cemented carbonate sands. Géotechnique 43(1): 53-67.

Cuccovillo T and Coop MR (1999) On the mechanics of structured sands. Géotechnique 49(6): 741-760.

Cuss RJ, Rutter EH and Holloway RF (2003) The application of critical state soil mechanics to the mechanical behaviour of porous sandstones. International Journal of Rock Mechanics \& Mining Sciences 40: 847-862.

David C, Menéndez B and Bernabé Y (1998) The mechanical behaviour of synthetic sandstone with varying brittle cement content. International Journal of Rock Mechanics and Mining Sciences 35(6): 759-779.

Desrues J, Lanier J and Stutz P (1985) Localization of the deformation in tests on sand samples. Engineering Fracture Mechanics 21(4): 909-921.

Desrues J, Chambon R, Mokni M and Mazerolle F (1996) Void ratio evolution inside shear bands in triaxial sand specimens studied by computed tomography. Géotechnique 46(3): 529-546.

Drucker DC and Prager W (1952) Soil mechanics and plastic analysis or limit design. Quarterly of Applied Mathematics 10(2): 157-165.

El Bied A, Sulem J and Martineau F (2002) Microstructure of shear zones in Fontainebleau sandstone. International Journal of Rock Mechanics \& Mining Sciences 39(7): 917-932.

Fernandez AL and Santamarina JC (2001) Effect of cementation on the small-strain parameters of sand. Canadian Geotechnical Journal 38(1): 191-199.

Finno RJ, Harris WW, Mooney MA and Viggiani G (1996) Strain localization and undrained steady state of sand. Journal of Geotechnical Engineering 122(6): 462-473.

Finno RJ, Harris WW, Mooney MA and Viggiani G (1997) Shear bands in plane strain compression of loose sand. Géotechnique 47(1): $149-165$.

Gens A and Nova R (1993) Conceptual bases for a constitutive model for bonded soils and weak rocks. Proceedings of the International Conference on Geotechnical Engineering of Hard Soils - Soft Rocks, Balkema, Rotterdam, pp. 485-494.

Hansen B (1958) Line ruptures regarded as narrow rupture zones - basic equations based on kinematic considerations. Proceedings of the Conference on Earth Pressure Problems, I, Brussels, Belgium, pp. 39-48.

Holt RM, Brignoli M and Kenter CJ (2000) Core quality: quantification of coring-induced rock alteration. International Journal of Rock Mechanics and Mining Sciences 37: 889-907.

Huang JT and Airey DW (1993) Effects of cement and density on an artificially cemented sand. Geotechnical Engineering of Hard Soils - Soft Rocks, Balkema, Rotterdam, pp. 553-560.

Huang JT and Airey DW (1998) Properties of artificially cemented carbonate sand. Journal of Geotechnical and Geoenvironmental Engineering 124(6): 492-499. 
Indraratna B, Balasubrammaniam AS and Khan MJ (1995) Effects of fly ash with lime and cement on the behavior of a soft clay. Quarterly Journal of Engineering Geology 28: 131-142.

Ismail MA, Joer HA and Randolph MF (2002) Sample preparation technique for artificially cemented soils. Geotechnical Testing Journal, ASTM 23(2): 171-177.

Katsman R and Aharonov E (2006) A study of compaction bands originating from cracks, notches, and compacted defects. Journal of Structural Geology 28(3): 508-518.

Kim MK and Lade PV (1988) Single hardening constitutive model for frictional materials, I. Plastic potential function. Computers and Geotechnics 5(4): 307-324.

Klein E, Baud P, Reuschlé T and Wang T-F (2001) Mechanical behaviour and failure mode of Bentheim Sandstone under triaxial compression. Physics and Chemistry of the Earth (A), 26(1-2): 21-25.

Kranz RL (1983) Microcracks in rocks: a review. Tectonophysics 100(1-3): 448-480.

Lade PV (1977) Elasto-plastic stress-strain theory for cohesionless soil with curved yield surfaces. International Journal of Solids and Structures 13: 1019-1035.

Lade PV (1993) Rock strength criteria: the theories and the evidence. In Comprehensive Rock Engineering, Principles, Practice \& Projects (Hudson JA (ed.)). Pergamon Press, Oxford, vol. 1, pp. 255-284.

Lade PV (2003) Analysis and prediction of shear banding under 3D conditions in granular materials. Soils and Foundations 43(4): 161-172.

Lade PV and Bopp PA (2005) Relative density effects on drained sand behavior at high pressures. Soils and Foundations 45(1): $1-13$.

Lade PV and Ibsen LB (1997) A study of the phase transformation and the characteristic lines of sand behavior. International Symposium on Deformation and Progressive Failure in Geomechanics (A. Asaoka, T. Adachi, and F. Oka (eds)). Pergamon Press, IS-Nagoya'97, Japan, pp. 353-358.

Lade PV and Kim MK (1988a) Single hardening constitutive model for frictional materials, II. Yield criterion and plastic work contours. Computers and Geotechnics 6(1): 13-29.

Lade PV and Kim MK (1988b) Single hardening constitutive model for frictional materials, III. Comparisons with experimental data. Computers and Geotechnics 6(1): 31-47.

Lade PV and Overton DD (1989) Cementation effects in frictional materials. Journal of Geotechnical Engineering 115(10): 1373-1387.

Lade PV and Prabucki M-J (1995) Softening and preshearing effects in sand. Soils and Foundations 35(4): 93-104.

Lade PV and Wang Q (2001) Analysis of shear banding in true triaxial tests on sand. Journal of Engineering Mechanics 127(8): 762-768.

Lagioia R and Nova R (1995) An experimental and theoretical study of the behaviour of a calcarenite in triaxial compression. Géotechnique 45(4): 633-648.
Lee KL (1965) Triaxial Compressive Strength of Saturated Sand under Seismic Loading Conditions. PhD dissertation, University of California, Berkeley.

Lee D-H, Jueng CH, Chen J-W, Lin H-M and Shieh W-H (1999) Stress paths and mechanical behavior of a sandstone in hollow cylinder tests. International Journal of Rock Mechanics and Mining Sciences 36(7): 857-870.

Lee D-H, Jueng CH, Chen J-W, Lin H-M and Yeh S-H (2002) Mechanical behavior of Tien-Liao mudstone in hollow cylinder tests. Canadian Geotechnical Journal 39(3): 744-756.

Leroueil S and Vaughan PR (1990) The general and congruent effect of structure in natural soils and weak rock. Géotechnique 40(3): 467-488.

Liao JJ, Yang M-T and Hsieh H-Y (1997) Direct tensile behavior of a transversely isotropic rock. International Journal of Rock Mechanics and Mining Sciences and Geomechanical Abstracts 34(5): 837-849.

Lo S-CR, Lade PV and Wardani SPR (2003) An experimental study of the mechanics of two weakly cemented soils. Geotechnical Testing Journal 26(3): 328-341.

Luong MP (1982) Stress-strain aspects of cohesionless soils under cyclic and transient loading. International Symposium on Soil under Cyclic and Transient Loading, Balkema, Rotterdam, pp. 315-324.

Miura N and Yamanouchi T (1973) Compressibility and drained shear characteristics of a sand under high confining pressure. Technological Reports of the Yamaguchi University, Japan, 1(2): 271-290.

Molenkamp F (1985) Comparison of frictional material models with respect to shear band initiation. Géotechnique 35(2): 127-143.

Muhlhaus HB and Vardoulakis I (1987) Thickness of shear bands in granular materials. Géotechnique 37(3): 271-283.

Nemat-Nasser S and Okada N (2001) Radiographic and microscopic observation of shear bands in granular materials. Géotechnique 51(9): 753-765.

Nova R, Castellanza R and Tamagnini C (2003) A constitutive model for bonded geomaterials subject to mechanical and/or chemical degradation. International Journal for Numerical and Analytical Methods in Geomechanics 27: 705-732.

Olsson WA (1999) Theoretical and experimental investigation of compaction bands in porous rock. Journal of Geophysical Research 104(B4): 7219-7228.

Ord A, Vardoulakis I and Kajewski R (1991) Shear band formation in Gosford Sandstone. International Journal of Rock Mechanics and Mining Sciences \& Geomechanics Abstracts 28(5): 397-409.

Parry RHG and Nadarajah V (1973) Volumetric yield locus for lightly overconsolidated clay. Géotechnique 23(3): 450-453.

Pestana JM and Whittle AJ (1995) Compression model for cohesionless soils. Géotechnique 45(4): 611-631.

Pestman BJ and Van Munster JG (1996) An acoustic emission study of damage development and stress-memory effects in sandstone. International Journal of Rock Mechanics and Mining Sciences \& Geomechanics Abstracts 33(6): 585-593. 
Reddy KR and Saxena SK (1993) Effects of cementation on stress-strain and strength characteristics of sand. Soils and Foundations 33(4): 121-134.

Rice JR (1976) The localization of plastic deformation. Proceedings of the 4th Conference on Theoretical and Applied Mechanics (Koiter WT (ed.)). North-Holland, Amsterdam, pp. 207-229.

Rotta GV, Consoli NC, Prietto PDM and Graham J (2003) Isotropic yielding in an artificially cemented soil cured under stress. Géotechnique 53(5): 493-501.

Rowe PW (1962) The stress-dilatancy relation for static equilibrium of an assembly of particles in contact. Proceedings of the Royal Society, Series A 269: 500-527.

Rudnicki JW and Rice JR (1975) Conditions for the localization of deformation in pressure-sensitive dilatant materials. Journal of Mechanics and Physics of Solids 23: 371-394.

Schnaid F, Prietto PDM and Consoli NC (2001) Characterization of cemented sand in triaxial compression. Journal of Geotechnical and Geoenvironmental Engineering 127(10): 857-868.

Sharma SS and Fahey M (2003) Degradation of stiffness of cemented calcareous soil in cyclic triaxial tests. Journal of Geotechnical and Geoenvironmental Engineering 129(7): 619-629.

Sulem J and Ouffroukh H (2006) Shear banding in drained and undrained triaxial tests on a saturated sandstone: Porosity and permeability evolution. International Journal of Rock Mechanics and Mining Sciences 43(2): 292-310.

Talesnick ML, Katz A and Ringel M (2000) An investigation of the elastic stress-strain behavior of a banded sandstone and a sandstone-like material. Geotechnical Testing Journal 23(3): 257-273.

Tatsuoka F and Ishihara K (1974) Yielding of sand in triaxial compression. Soils and Foundations 14: 63-76.

Tatsuoka F, Nakamura S, Huang CC and Tani K (1990) Strength anisotropy and shear band direction in plane strain tests of sand. Soils and Foundations 30(1): 35-54.

Toll DG and Malandraki V (1993) Triaxial testing of a weakly bonded soil. Geotechnical Engineering of Hard Soils - Soft Rocks, Balkema, Rotterdam, pp. 817-823.

Trads N and Lade PV (2014) Experimental evidence of truly elastic behavior of artificial sandstone inside the cementation yield surface. Rock Mechanics and Rock Engineering 47(2): 335-345, http://dx.doi.org/10.1007/s00603-013-0403-x.
Vardoulakis I (1980) Shear band inclination and shear modulus of sand in biaxial tests. International Journal of Numerical and Analytical Methods in Geomechanics 4: 103-119.

Vardoulakis I (1996a) Deformation of water-saturated sand: I. Uniform undrained deformation and shear banding. Geotechnique 46(3): 441-456.

Vardoulakis I (1996b) Deformation of water-saturated sand: II. Effect of pore water flow and shear banding. Géotechnique 46(3): 457-472.

Vardoulakis I, Goldscheider M and Gudehus G (1978) Formation of shear bands in sand bodies as a bifurcation problem. International Journal for Numerical and Analytical Methods in Geomechanics 2(2): 99-128.

Vermeer PA (1982) A simple shear-band analysis using compliances. Proceedings of the IUTAM Symposium on Deformation and Failure of Granular Materials, Balkema, Rotterdam, pp. 493-499.

Vesic AS and Clough GW (1968) Behavior of granular materials under high stresses. Journal of the Soil Mechanics and Foundations Division, ASCE 94(SM3): 661-688.

Wang Q and Lade PV (2001) Shear banding in true triaxial tests and its effect on failure in sand. Journal of Engineering Mechanics 127(8): 754-761.

Wong T-F, David C and Zhu W (1997) The transition from brittle faulting to cataclastic flow in porous sandstones: Mechanical deformation. Journal of Geophysical Research 102(B2): 3009-3025.

Wu XY, Baud P and Wong T-F (2000) Micromechanics of compressive failure and spatial evolution of anisotropic damage in Darley Dale sandstone. International Journal of Rock Mechanics and Mining Sciences 37(1-2): 143-160.

Yamamuro JA, Bopp PA and Lade PV (1996) One-dimensional compression of sands at high pressures. Journal of Geotechnical Engineering 122(2): 147-154.

Yoshida T, Tatsuoka F, Siddiquee MSA, Kamegai Y and Park C-S (1993) Shear banding in sands observed in plane strain compression. Proceedings of the 3rd International Workshop on Localisation and Bifurcation - Theory for Soils and Rocks, Balkema, Rotterdam, pp. 165-179.

Yun TS and Santamarina JC (2005) Decementation, softening, and collapse: changes in small-strain shear stiffness in $K_{0}$ loading. Journal of Geotechnical and Geoenvironmental Engineering 131(3): 350-358.

\section{WHAT DO YOU THINK?}

To discuss this paper, please submit up to 500 words to the editor at journals@ice.org.uk. Your contribution will be forwarded to the author(s) for a reply and, if considered appropriate by the editorial panel, will be published as a discussion in a future issue of the journal. 